\title{
Enantioselective Total Synthesis of Cepharatines via Bioinspired Ring Reconstruction
}

Minami Odagi, ${ }^{\text {Taisei Matoba, Kazuo Nagasawa* }}$

Department of Biotechnology and Life Science, Tokyo University of Agriculture and Technology, 2-2416, Naka-cho, Koganei, Tokyo 184-8588 (Japan)

E-mail: odagi@cc.tuat.ac.jp; knaga@cc.tuat.ac.jp

Table of Contents

1. Scheme for Preparation of Compound 15

2. Copy of HPLC Charts of S5

3. Comparison of ${ }^{1} \mathrm{H}$ and ${ }^{13} \mathrm{C}$ NMR Signals of Natural and Synthetic Materials

4. ${ }^{1} \mathrm{H}$ and ${ }^{13} \mathrm{C}$ NMR Spectra

S-12 


\section{Scheme for Preparation of Compound 15}<smiles>COc1cc(Br)c(C=O)cc1OC</smiles>

S1<smiles>COc1cc(Br)c(C(C#N)O[Na])cc1OC</smiles>

S2<smiles>C=CCc1ccc(OC)cc1COC</smiles>

1) S3, LiHMDS, THF $-78^{\circ} \mathrm{C}$ to $0^{\circ} \mathrm{C}$

2) TBAF, THF, $0{ }^{\circ} \mathrm{C}$

( $71 \%$ yield)<smiles>C=CCc1ccc(OC)cc1CC(=O)c1cc(OC)c(OC)cc1Br</smiles>

S4

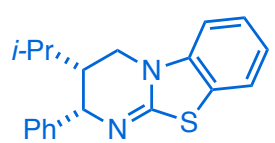<smiles>C=CCc1ccc(OC)cc1CC(O)c1cc(OC)c(OC)cc1Br</smiles>

(39\% yield, $99 \%$ ee)

(-)-S5

TIPSCI

imidazole DMF, $65^{\circ} \mathrm{C}$

(95\% yield)<smiles>C=CCc1ccc(OC)cc1C[C@H](OC(C)=O)c1cc(OC)c(OC)cc1Br</smiles>

( $57 \%$ yield, $35 \%$ ee)

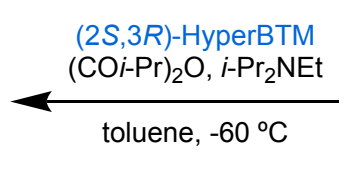<smiles>C=CCc1ccc(OC)cc1CC(O)c1cc(OC)c(OC)cc1Br</smiles><smiles>C=CCc1ccc(OC)cc1CC(O[In])c1cc(OC)c(OC)cc1Br</smiles>

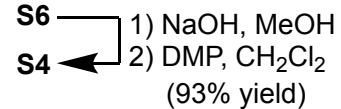
(93\% yield)<smiles></smiles>

15

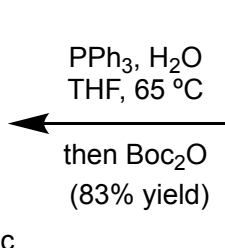

(83\% yield)<smiles></smiles>

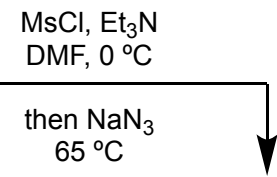

(82\% yield)<smiles>COc1ccc(CCN)c(CC(O[In])c2cc(OC)c(OC)cc2Br)c1</smiles>

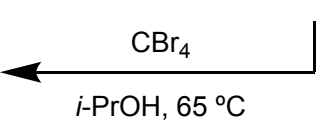

$(91 \%$ yield $)$ 


\section{Copy of HPLC Charts of S5}

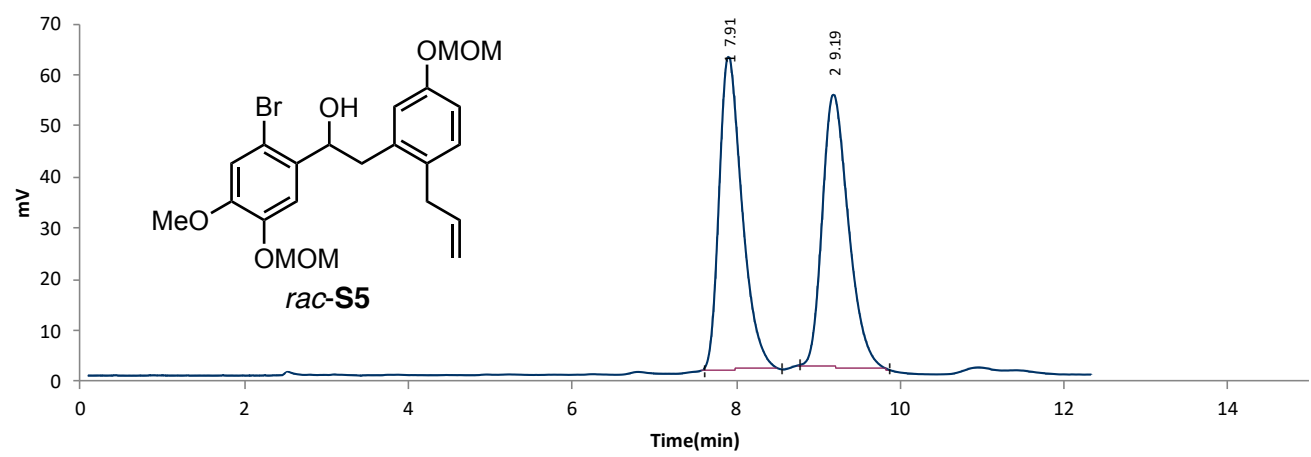

\begin{tabular}{|r|r|r|r|r|r|}
\hline No. & \multicolumn{2}{|c|}{ Area } & \multicolumn{2}{c|}{ Area(\%) } & \multicolumn{1}{l}{ Height } \\
\hline 1 & 7.91 & 1187373.247 & 50.0925 & 61404 \\
\hline 2 & 9.19 & 1182986.8 & 49.9075 & 53397 \\
\hline & & & 2370360.047 & 100 & 114801 \\
\hline
\end{tabular}

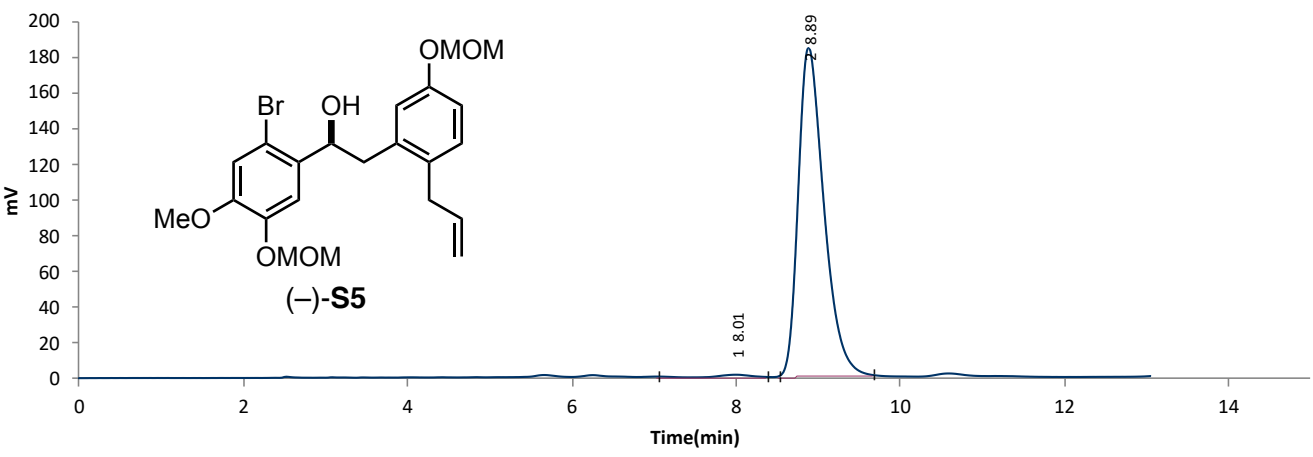

\begin{tabular}{|c|c|c|c|c|}
\hline No. & $\mathrm{Rt}$ & Area & Area(\%) & Height \\
\hline 1 & 8.01 & 13957.9 & 0.3504 & 1164 \\
\hline 2 & 8.89 & 3969800.7 & 99.6496 & 183708 \\
\hline & & 3983758.6 & 100 & 184872 \\
\hline
\end{tabular}

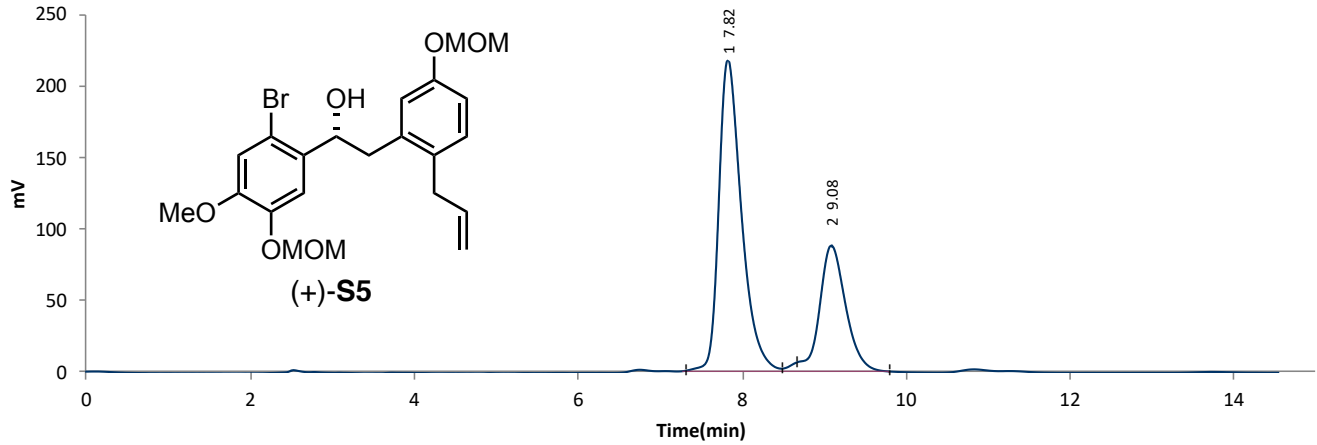

\begin{tabular}{|r|r|r|r|r|r|}
\hline No. & \multicolumn{2}{|c|}{ Area } & \multicolumn{2}{c|}{ Area(\%) } & Height \\
\hline 1 & 7.82 & 4200429.868 & 67.9235 & 218173 \\
\hline 2 & 9.08 & 1983625.59 & 32.0765 & 88194 \\
\hline & & 6184055.458 & 100 & 306367 \\
\hline
\end{tabular}




\section{Comparison of ${ }^{1} \mathrm{H}$ and ${ }^{13} \mathrm{C}$ NMR Signals of Natural and Synthetic Materials}

\section{3-1. Comparison of ${ }^{1} \mathrm{H}$ and ${ }^{13} \mathrm{C}$ NMR Signals of Cepharatine A}<smiles>COc1ccc2c(c1O)[C@@]1(C=O)CCN(C)[C@]3(O)C[C@]1(O)C(=O)C=C3C=C2</smiles>

\section{Cepharatine A}

\begin{tabular}{lcc}
\hline${ }^{1} \mathrm{H} N M R$ & Natural $\left(400 \mathrm{MHz}, \mathrm{CDCl}_{3}\right)^{[3]}$ & $\begin{array}{c}\text { Synthetic } 6\left(500 \mathrm{MHz}, \mathrm{CDCl}_{3}\right) \\
\delta / \mathrm{ppm}\end{array}$ \\
\hline 1 & $\delta / \mathrm{ppm}$ & $6.77(\mathrm{~d}, J=8.6 \mathrm{~Hz})$ \\
2 & $6.77(\mathrm{~d}, J=8.4 \mathrm{~Hz})$ & $6.79(\mathrm{~d}, J=9.2 \mathrm{~Hz})$ \\
5 & $6.79(\mathrm{~d}, J=8.4 \mathrm{~Hz})$ & $2.22(\mathrm{~d}, J=2.9 \mathrm{~Hz})$ \\
& $2.21(\mathrm{~m})$ & $3.91(\mathrm{~d}, J=13.2 \mathrm{~Hz})$ \\
8 & $3.95(\mathrm{~d}, J=12.8 \mathrm{~Hz})$ & $6.13(\mathrm{~s})$ \\
9 & $6.13(\mathrm{~s})$ & $6.30(\mathrm{~d}, J=9.2 \mathrm{~Hz})$ \\
10 & $6.29(\mathrm{~d}, J=9.6 \mathrm{~Hz})$ & $6.70(\mathrm{~d}, J=9.2 \mathrm{hz})$ \\
15 & $6.71(\mathrm{~d}, J=9.6 \mathrm{~Hz})$ & $1.42-1.34(\mathrm{~m})$ \\
& $1.40(\mathrm{~m})$ & $2.74-2.58(\mathrm{~m})$ \\
16 & $2.66(\mathrm{~m})$ & $2.74-2.58(\mathrm{~m})$ \\
& $2.74(\mathrm{~m})$ & $2.91-2.84(\mathrm{~m})$ \\
$3-\mathrm{OMe}$ & $2.90(\mathrm{~m})$ & $3.94(\mathrm{~s})$ \\
$\mathrm{NMe}$ & $3.94(\mathrm{~s})$ & $2.25(\mathrm{~s})$
\end{tabular}

\begin{tabular}{lcc}
\hline${ }^{13} \mathrm{C} \mathrm{NMR}$ & Natural $\left(100 \mathrm{MHz}, \mathrm{CDCl}_{3}\right)^{[3]}$ & Synthetic $6\left(125 \mathrm{MHz}, \mathrm{CDCl}_{3}\right)$ \\
\hline 1 & $\delta / \mathrm{ppm}$ & $\delta / \mathrm{ppm}$ \\
2 & 121.2 & 121.3 \\
3 & 108.7 & 108.7 \\
4 & 148.1 & 148.0 \\
5 & 144.4 & 144.4 \\
6 & 43.4 & 43.5 \\
7 & 83.2 & 83.2 \\
8 & 194.0 & 194.1 \\
9 & 124.0 & 124.1 \\
10 & 123.3 & 123.4 \\
11 & 136.1 & 136.0 \\
12 & 125.5 & 125.6 \\
13 & 125.4 & 125.4 \\
14 & 44.3 & 44.3 \\
15 & 161.6 & 161.5 \\
16 & 31.1 & 31.2 \\
$3-\mathrm{OMe}$ & 46.6 & 46.6 \\
$\mathrm{NMe}$ & 56.1 & 56.2 \\
& 36.2 & 36.2
\end{tabular}


${ }^{1} \mathrm{H}$ NMR Spectrum for Natural Cepharatine A
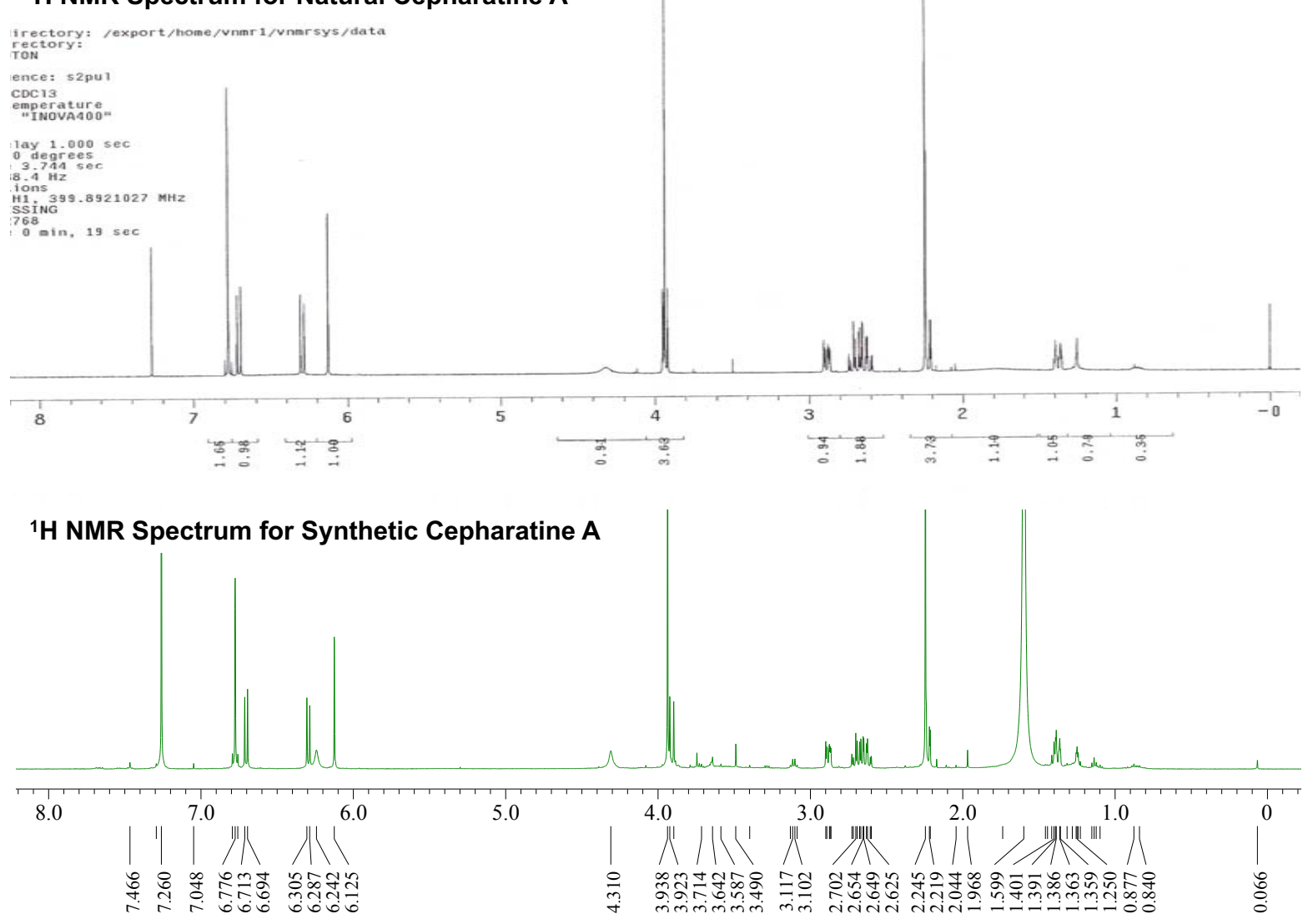

${ }^{13} \mathrm{C}$ NMR Spectrum for Natural Cepharatine A

ited

$12.0 \mathrm{~Hz}$

$8 \mathrm{~min}, 26 \mathrm{sec}$

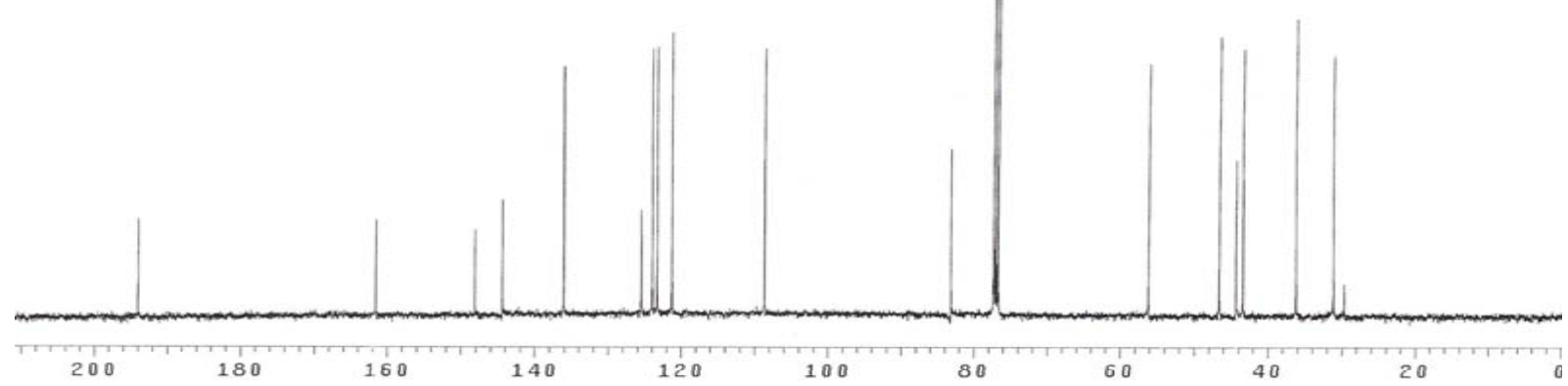

${ }^{13} \mathrm{C}$ NMR Spectrum for Synthetic Cepharatine A

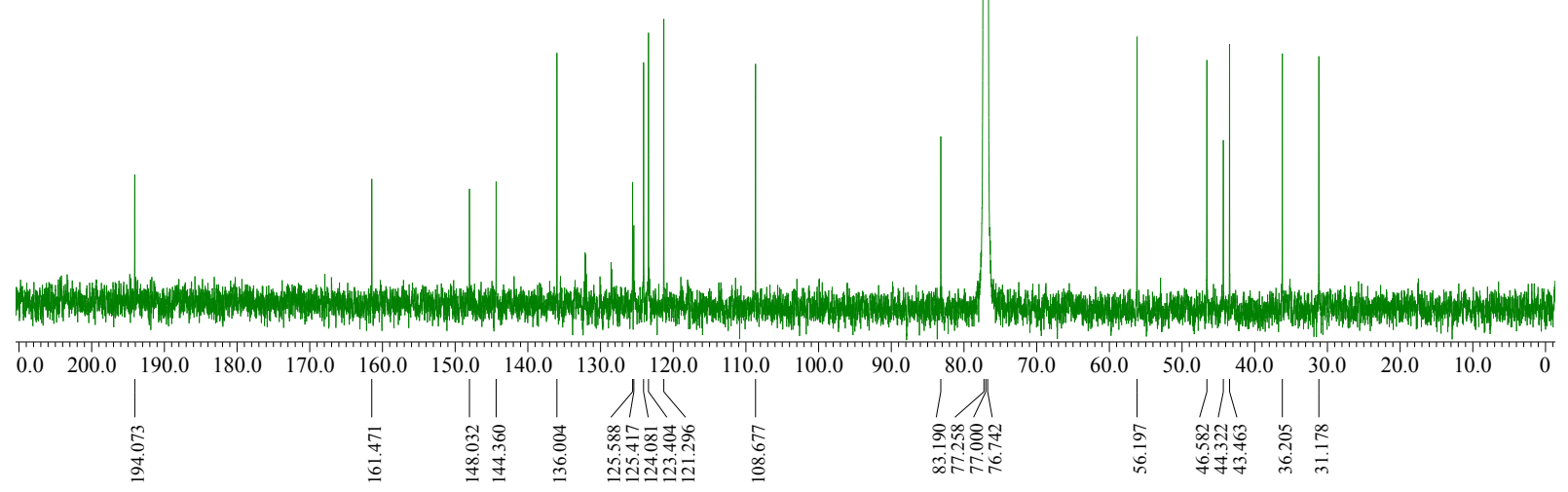




\section{3-2. Comparison of ${ }^{1} \mathrm{H}$ and ${ }^{13} \mathrm{C}$ NMR Signals of Cepharatine $\mathrm{B}$}<smiles>CC[C@]1(O)C(=O)C=C2C=Cc3cc(O)c(OC)cc3[C@@]2(C)CCN1C</smiles>

Cepharatine B

\begin{tabular}{lcc}
\hline${ }^{1} \mathrm{H} \mathrm{NMR}$ & Natural $\left(400 \mathrm{MHz}, \mathrm{CDCl}_{3}\right)^{[3]}$ & $\begin{array}{c}\text { Synthetic } 7\left(500 \mathrm{MHz}, \mathrm{CDCl}_{3}\right) \\
\delta / \mathrm{ppm}\end{array}$ \\
\hline 1 & $6 / \mathrm{ppm}$ & $6.80(\mathrm{~s})$ \\
4 & $6.80(\mathrm{~s})$ & $6.97(\mathrm{~s})$ \\
5 & $2.33(\mathrm{~m})$ & $2.30(\mathrm{dd}, J=12.6,2.9 \mathrm{~Hz})$ \\
8 & $2.77(\mathrm{~d}, J=12.4 \mathrm{~Hz})$ & $2.71(\mathrm{~d}, J=12.6 \mathrm{~Hz})$ \\
9 & $6.16(\mathrm{~s})$ & $6.15(\mathrm{~s})$ \\
10 & $6.32(\mathrm{~d}, J=9.2 \mathrm{~Hz})$ & $6.31(\mathrm{~d}, J=9.7 \mathrm{~Hz})$ \\
15 & $6.72(\mathrm{~d}, J=9.2 \mathrm{~Hz})$ & $6.71(\mathrm{~d}, J=9.2 \mathrm{~Hz})$ \\
& $1.59(\mathrm{~m})$ & $1.58(\mathrm{~d}, J=14.3 \mathrm{~Hz})$ \\
16 & $2.02(\mathrm{~m})$ & $1.95(\mathrm{td}, J=13.2,5.2 \mathrm{~Hz})$ \\
& $2.66(\mathrm{~m})$ & $2.61(\mathrm{td}, J=12.7,3.8 \mathrm{~Hz})$ \\
$3-\mathrm{OMe}$ & $2.90(\mathrm{~m})$ & $2.86(\mathrm{ddd}, J=12.6,5.2,1.7 \mathrm{~Hz})$ \\
NMe & $3.92(\mathrm{~s})$ & $3.91(\mathrm{~s})$ \\
& $2.18(\mathrm{~s})$ & $2.24(\mathrm{~s})$
\end{tabular}

\begin{tabular}{lcc}
\hline${ }^{13} \mathrm{C} \mathrm{NMR}$ & Natural $\left(100 \mathrm{MHz}, \mathrm{CDCl}_{3}\right)^{[3]}$ & Synthetic $7\left(125 \mathrm{MHz}, \mathrm{CDCl}_{3}\right)$ \\
\hline 1 & $\delta / \mathrm{ppm}$ & $\delta / \mathrm{ppm}$ \\
2 & 114.7 & 114.7 \\
3 & 144.4 & 144.4 \\
4 & 147.7 & 147.7 \\
5 & 106.9 & 106.9 \\
6 & 44.8 & 44.9 \\
7 & 83.1 & 83.0 \\
8 & 193.3 & 193.5 \\
9 & 124.1 & 124.1 \\
10 & 123.2 & 123.3 \\
11 & 135.7 & 135.6 \\
12 & 135.1 & 135.2 \\
13 & 124.0 & 124.2 \\
14 & 43.6 & 43.7 \\
15 & 161.6 & 161.5 \\
16 & 38.1 & 38.3 \\
$3-\mathrm{OMe}$ & 46.8 & 46.9 \\
$\mathrm{NMe}$ & 56.0 & 56.0 \\
& 35.9 & 36.0
\end{tabular}


${ }^{1} \mathrm{H}$ NMR Spectrum for Natural Cepharatine B

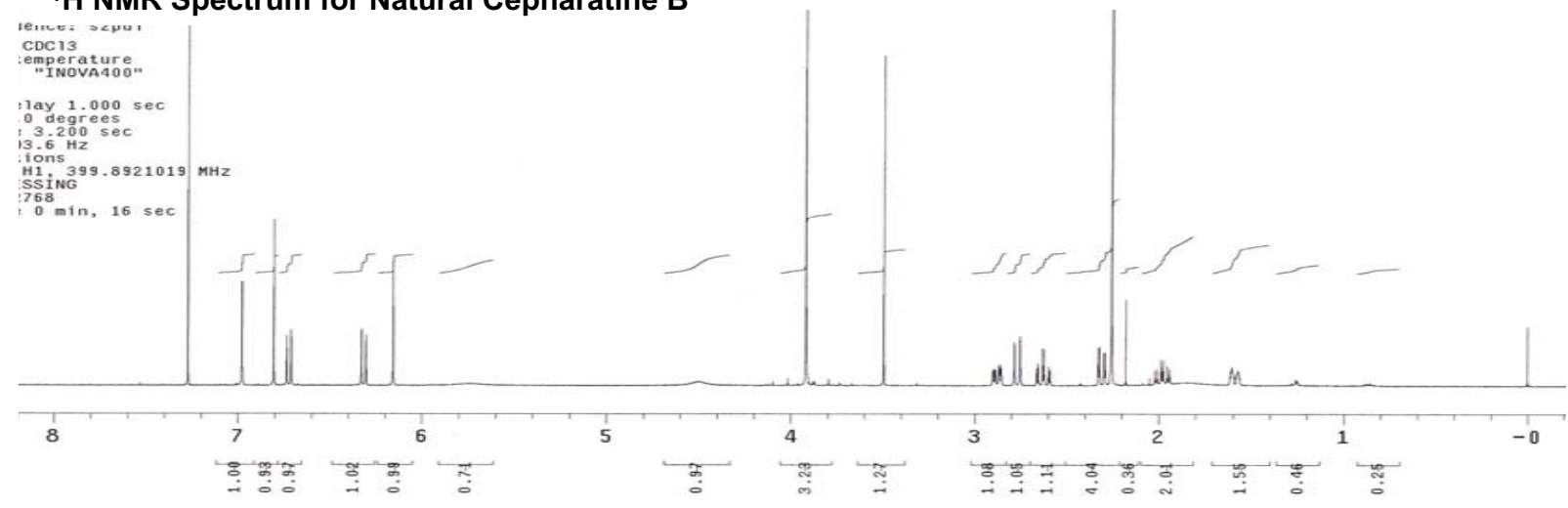

${ }^{1} \mathrm{H}$ NMR Spectrum for Synthetic Cepharatine B

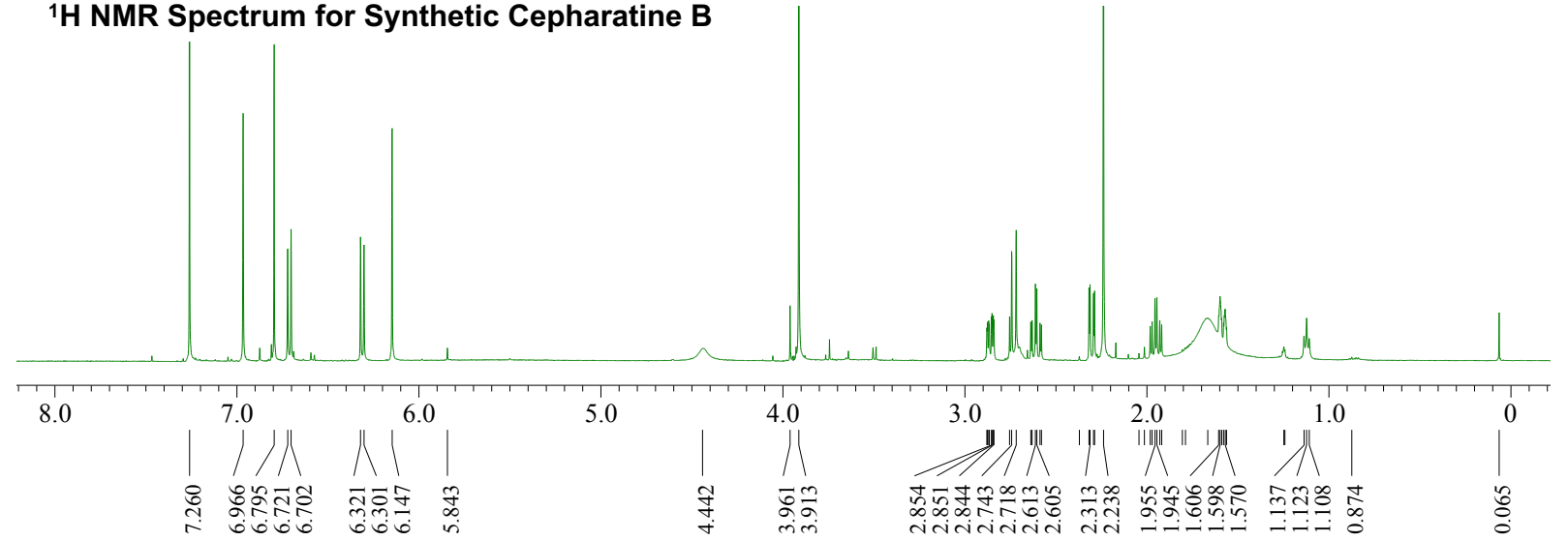

${ }^{13}$ C NMR Spectrum for Natural Cepharatine B

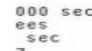
$z^{\text {sec }}$
5
0.5529556
9.894111
$9 H z$

ted
$1.0 \mathrm{~Hz}$

$1.0 \mathrm{~Hz}$
$8 \mathrm{~min}, 2 \mathrm{sec}$

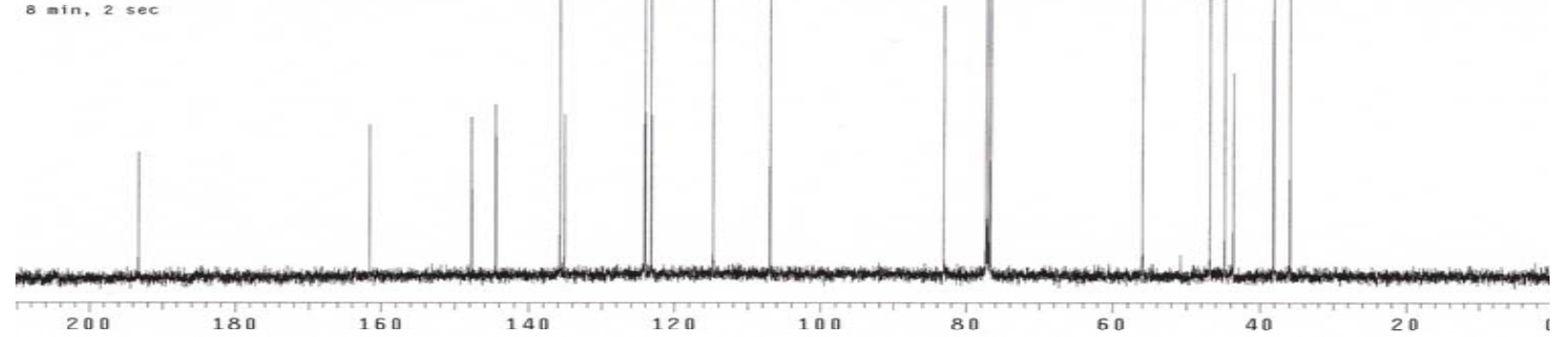

${ }^{13}$ C NMR Spectrum for Synthetic Cepharatine B

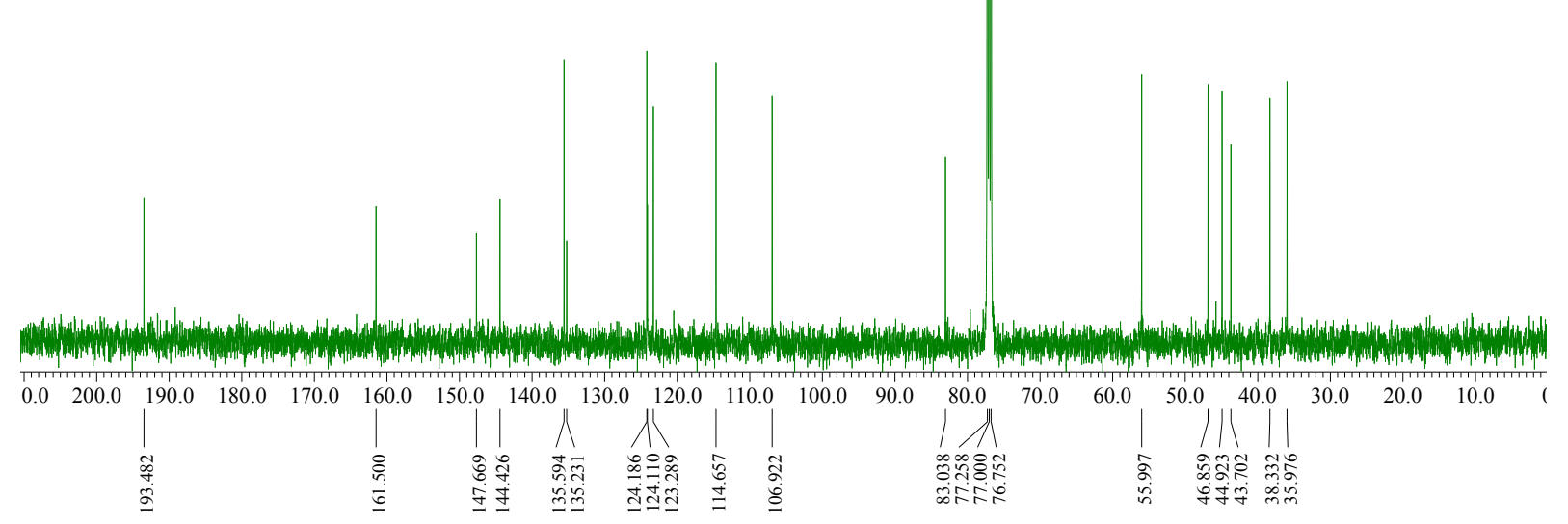




\section{3-3. Comparison of ${ }^{1} \mathrm{H}$ and ${ }^{13} \mathrm{C}$ NMR Signals of Cepharatine $\mathrm{C}$}<smiles>COc1ccc2c(c1O)[C@@]1(C(=O)C=O)CCN(C)[C@@]3(OC)C=CC=CC[C@@]21C3</smiles>

\section{Cepharatine C}

\begin{tabular}{lcc}
\hline${ }^{1} H$ NMR & Natural $\left(400 \mathrm{MHz}, \mathrm{CD}_{3} \mathrm{OD}\right)^{[3]}$ & $\begin{array}{c}\text { Synthetic } 8\left(500 \mathrm{MHz}, \mathrm{CD}_{3} \mathrm{OD}\right) \\
\delta / \mathrm{ppm}\end{array}$ \\
\hline 1 & $\delta / \mathrm{ppm}$ & $6.80(\mathrm{~d}, J=8.6 \mathrm{~Hz})$ \\
2 & $6.77(\mathrm{~d}, J=8.4 \mathrm{~Hz})$ & $6.89(\mathrm{~d}, J=8.0 \mathrm{~Hz})$ \\
5 & $6.88(\mathrm{~d}, J=8.4 \mathrm{~Hz})$ & $2.04(\mathrm{dd}, J=12.3,2.6 \mathrm{~Hz})$ \\
8 & $2.02(\mathrm{~m})$ & $4.16(\mathrm{~d}, J=12.6 \mathrm{~Hz})$ \\
9 & $4.14(\mathrm{~d}, J=12.4 \mathrm{~Hz})$ & $6.04(\mathrm{~s})$ \\
10 & $6.03(\mathrm{~s})$ & $6.33(\mathrm{~d}, J=9.2 \mathrm{~Hz})$ \\
15 & $6.30(\mathrm{~d}, J=9.2 \mathrm{~Hz})$ & $6.78(\mathrm{~d}, J=10.3 \mathrm{~Hz})$ \\
& $6.80(\mathrm{~d}, J=9.2 \mathrm{~Hz})$ & $1.34-1.26(\mathrm{~m})$ \\
16 & $1.29(\mathrm{~m})$ & $2.67(\mathrm{td}, J=13.2,5.2 \mathrm{~Hz})$ \\
& $2.69(\mathrm{~m})$ & $2.52(\mathrm{td}, J=12.6,3.4 \mathrm{~Hz})$ \\
$3-\mathrm{OMe}$ & $2.55(\mathrm{~m})$ & $2.85(\mathrm{ddd}, J=12.0,5.2,1.2 \mathrm{~Hz})$ \\
$6-\mathrm{OMe}$ & $2.85(\mathrm{~m})$ & $3.91(\mathrm{~s})$ \\
$\mathrm{NMe}$ & $3.90(\mathrm{~s})$ & $3.32(\mathrm{~s})$ \\
& $3.31(\mathrm{~s})$ & $2.11(\mathrm{~s})$
\end{tabular}

\begin{tabular}{lcc}
\hline${ }^{13} \mathrm{C} \mathrm{NMR}$ & Natural $\left(100 \mathrm{MHz}, \mathrm{CD}_{3} \mathrm{OD}\right)^{[3]}$ & Synthetic 8 $\left(125 \mathrm{MHz}, \mathrm{CD}_{3} \mathrm{OD}\right)$ \\
\hline 1 & $\delta / \mathrm{ppm}$ & $\delta / \mathrm{ppm}$ \\
2 & 122.6 & 122.6 \\
3 & 110.4 & 110.5 \\
4 & 150.8 & 150.8 \\
5 & 146.5 & 146.5 \\
6 & 40.1 & 40.2 \\
7 & 88.8 & 88.9 \\
8 & 193.6 & 193.7 \\
9 & 126.4 & 126.5 \\
10 & 123.7 & 123.7 \\
11 & 137.9 & 137.9 \\
12 & 126.8 & 126.81 \\
13 & 126.7 & 126.78 \\
14 & 45.4 & 45.4 \\
15 & 162.7 & 162.6 \\
16 & 32.0 & 32.0 \\
$3-O M e$ & 47.7 & 47.8 \\
$6-O M e$ & 56.6 & 56.6 \\
NMe & 49.0 & $* * *$ \\
*** Overlapped with $\mathrm{CD}_{3} \mathrm{OD}^{\prime s}$ peak. & 36.9 & 36.9 \\
& &
\end{tabular}


${ }^{1} \mathrm{H}$ NMR Spectrum for Natural Cepharatine C

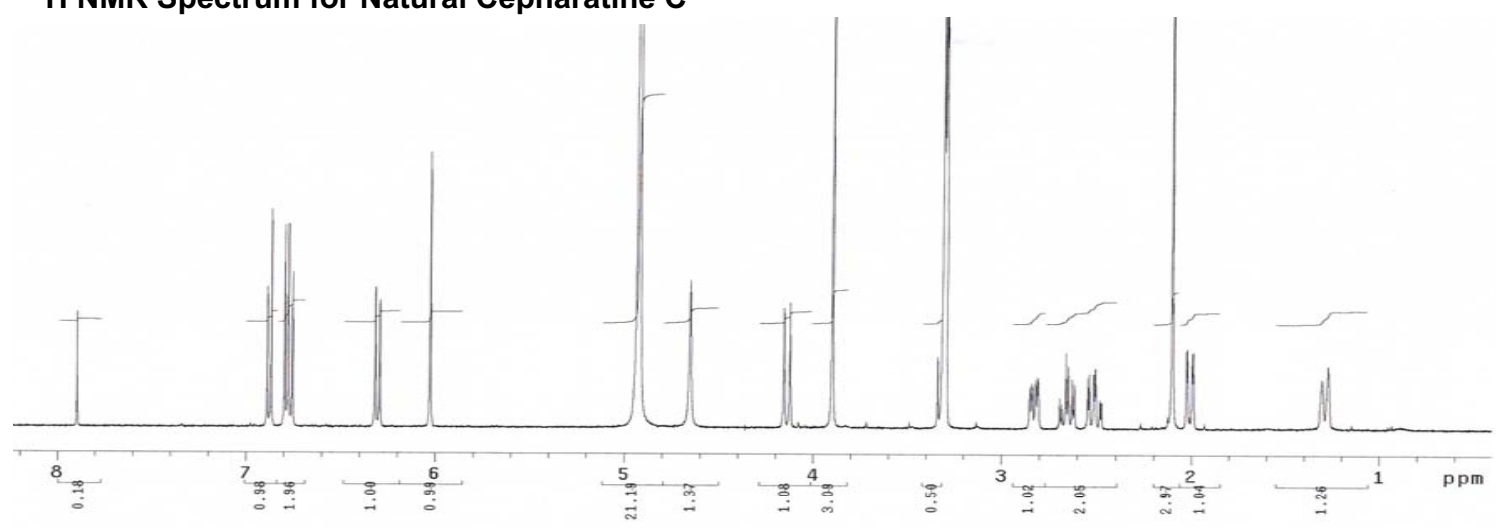

${ }^{1} \mathrm{H}$ NMR Spectrum for Synthetic Cepharatine C

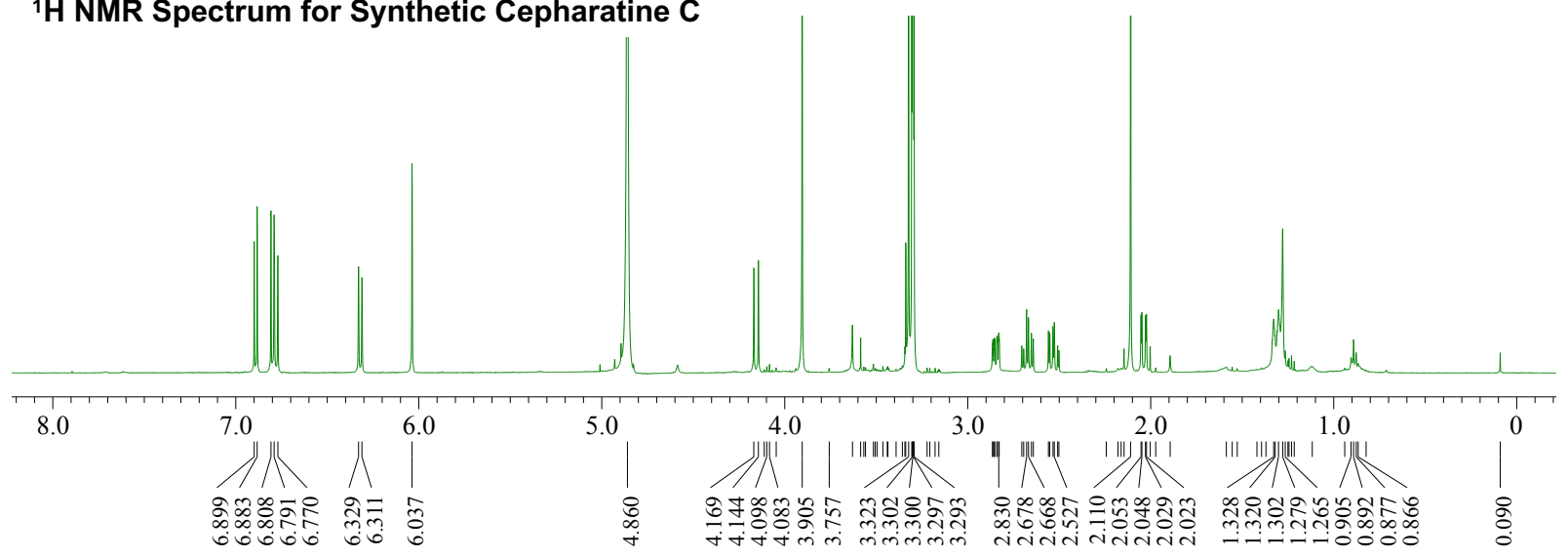

${ }^{13}$ C NMR Spectrum for Natural Cepharatine C

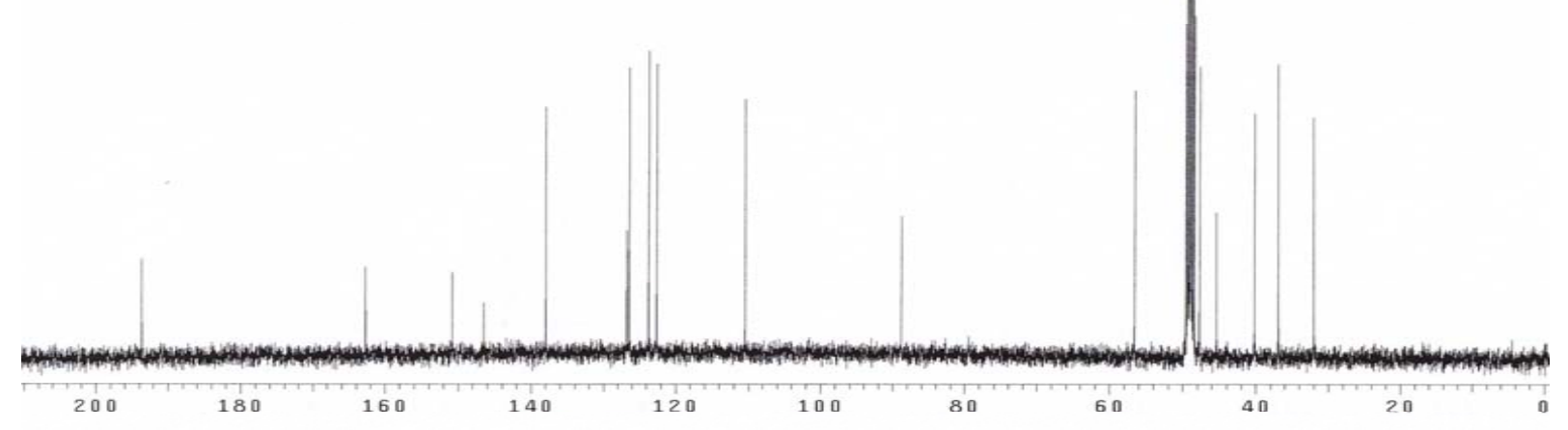

${ }^{13} \mathrm{C}$ NMR Spectrum for Synthetic Cepharatine C

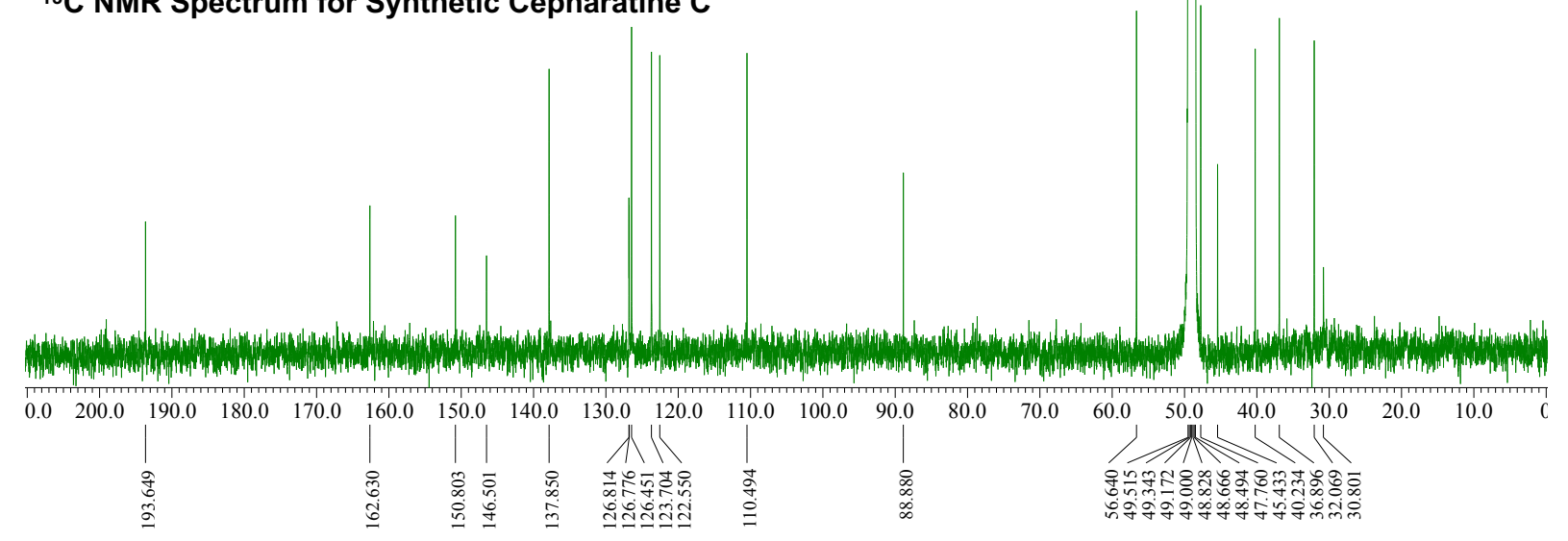




\section{3-4. Comparison of ${ }^{1} \mathrm{H}$ and ${ }^{13} \mathrm{C}$ NMR Signals of Cepharatine D}<smiles>COc1cc2c(cc1OC)[C@@]1(C=C2)CCN(C)[C@@]2(O)C=CC(=O)[C@@]1(O)C2</smiles>

\section{Cepharatine D}

\begin{tabular}{lcc}
\hline${ }^{1} \mathrm{H} N M R$ & Natural $\left(400 \mathrm{MHz}, \mathrm{CD}_{3} \mathrm{OD}\right)^{[3]}$ & $\begin{array}{c}\text { Synthetic } \mathbf{9}\left(500 \mathrm{MHz}, \mathrm{CD}_{3} \mathrm{OD}\right) \\
\delta / \mathrm{ppm}\end{array}$ \\
\hline 1 & $\delta / \mathrm{ppm}$ & $6.91(\mathrm{~s})$ \\
4 & $6.89(\mathrm{~s})$ & $7.07(\mathrm{~s})$ \\
5 & $7.06(\mathrm{~s})$ & $2.22(\mathrm{dd}, J=12.0,2.9 \mathrm{~Hz})$ \\
8 & $2.19(\mathrm{~m})$ & $2.68(\mathrm{~d}, J=12.6 \mathrm{~Hz})$ \\
9 & $2.67(\mathrm{~d}, J=12.0 \mathrm{~Hz})$ & $6.11(\mathrm{~s})$ \\
10 & $6.10(\mathrm{~s})$ & $6.38(\mathrm{~d}, J=9.7 \mathrm{~Hz})$ \\
15 & $6.36(\mathrm{~d}, J=9.2 \mathrm{~Hz})$ & $6.85(\mathrm{~d}, J=9.2 \mathrm{~Hz})$ \\
& $6.84(\mathrm{~d}, J=9.2 \mathrm{~Hz})$ & $1.54(\mathrm{~d}, J=13.7 \mathrm{~Hz})$ \\
16 & $1.59(\mathrm{~m})$ & $1.92(\mathrm{td}, J=13.2,5.2 \mathrm{~Hz})$ \\
& $2.02(\mathrm{~m})$ & $2.68(\mathrm{~d}, J=12.6 \mathrm{~Hz})$ \\
$2-\mathrm{OMe}$ & $2.66(\mathrm{~m})$ & $2.82(\mathrm{ddd}, J=13.0,5.0,1.6 \mathrm{~Hz})$ \\
$3-\mathrm{OMe}$ & $2.90(\mathrm{~m})$ & $3.91(\mathrm{~s})$ \\
$\mathrm{NMe}$ & $3.92(\mathrm{~s})$ & $3.84(\mathrm{~s})$ \\
& $3.83(\mathrm{~s})$ & $2.22(\mathrm{~s})$
\end{tabular}

\begin{tabular}{lcc}
\hline${ }^{13} \mathrm{C} \mathrm{NMR}$ & Natural $\left(100 \mathrm{MHz}, \mathrm{CD}_{3} \mathrm{OD}\right)^{[3]}$ & Synthetic $\mathbf{9}\left(125 \mathrm{MHz}, \mathrm{CD}_{3} \mathrm{OD}\right)$ \\
\hline$/ \mathrm{ppm}$ & $\delta / \mathrm{ppm}$ \\
\hline 1 & 113.4 & 113.5 \\
2 & 151.7 & 151.8 \\
3 & 149.5 & 149.6 \\
4 & 109.3 & 109.5 \\
5 & 46.4 & 46.4 \\
6 & 84.7 & 84.7 \\
7 & 194.7 & 194.7 \\
8 & 126.0 & 126.0 \\
9 & 124.1 & 124.1 \\
10 & 136.9 & 136.9 \\
11 & 137.0 & 137.1 \\
12 & 125.3 & 125.4 \\
13 & 44.8 & 44.9 \\
14 & 162.7 & 162.7 \\
15 & 39.0 & 39.0 \\
16 & 47.8 & 47.9 \\
$2-\mathrm{OMe}$ & 56.6 & 56.7 \\
$3-\mathrm{OMe}$ & 56.5 & 56.6 \\
$\mathrm{NMe}$ & 36.7 & 36.7
\end{tabular}




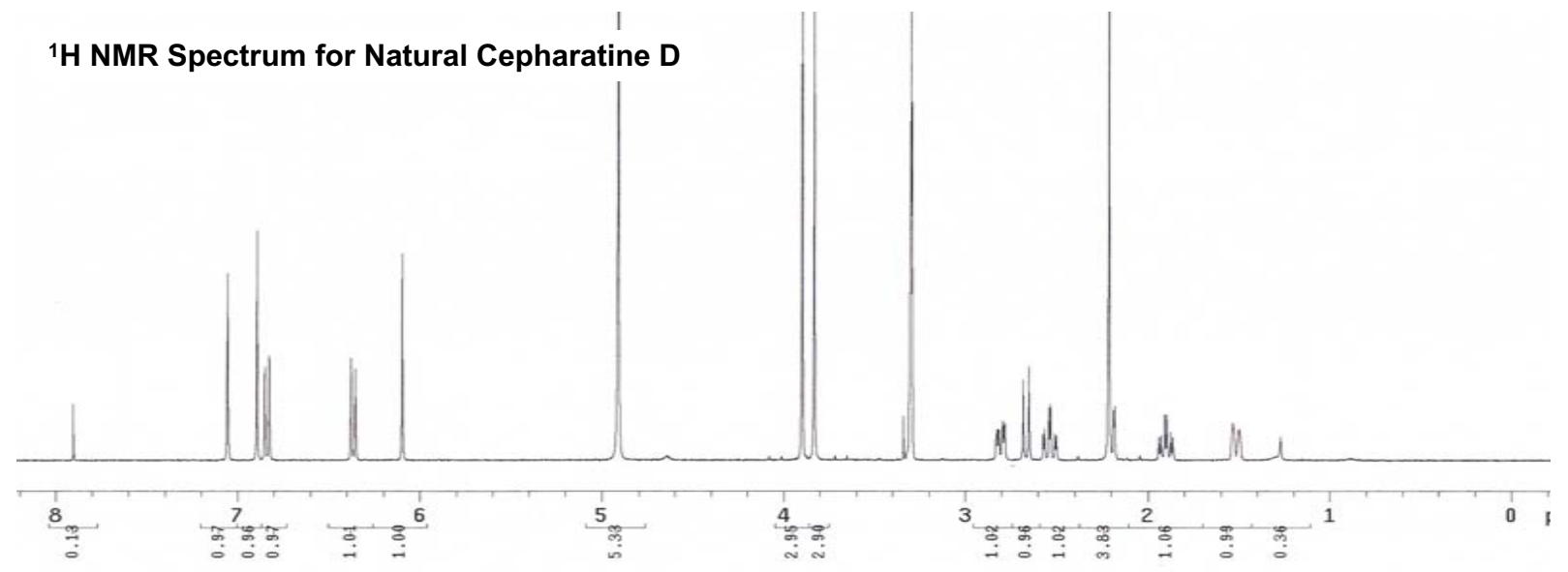

${ }^{1} \mathrm{H}$ NMR Spectrum for Synthetic Cepharatine D

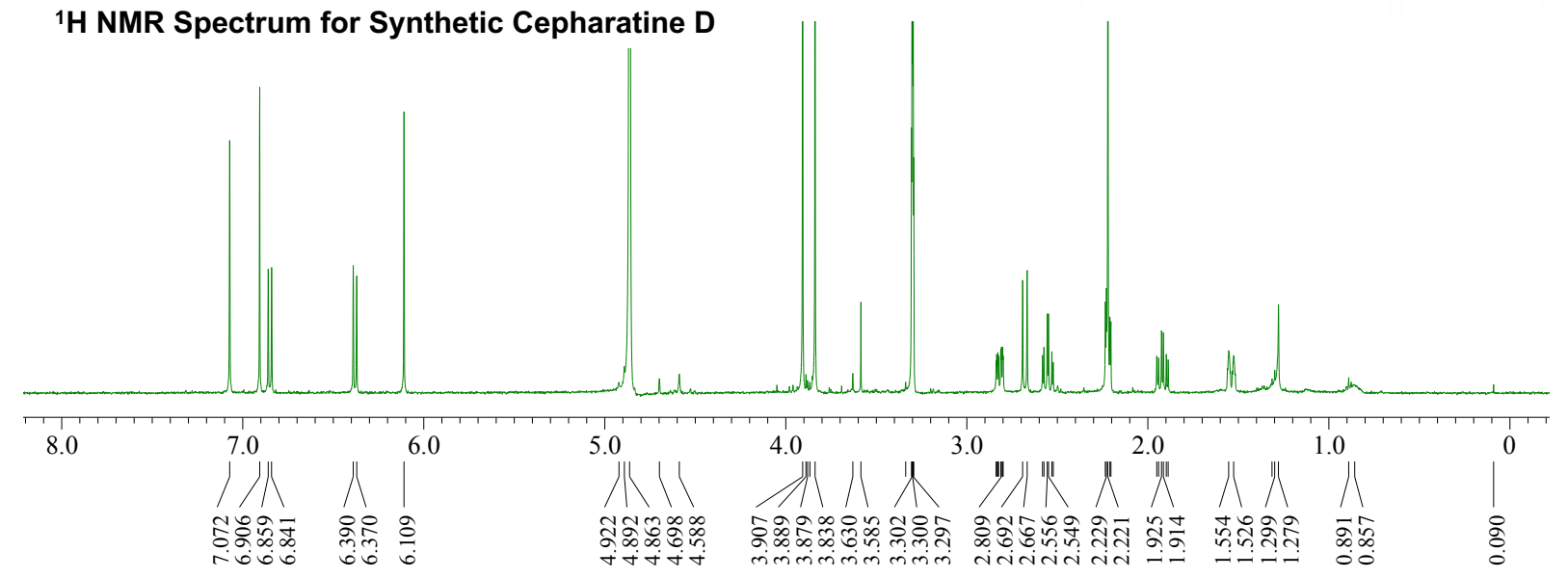

${ }^{13}$ C NMR Spectrum for Natural Cepharatine D

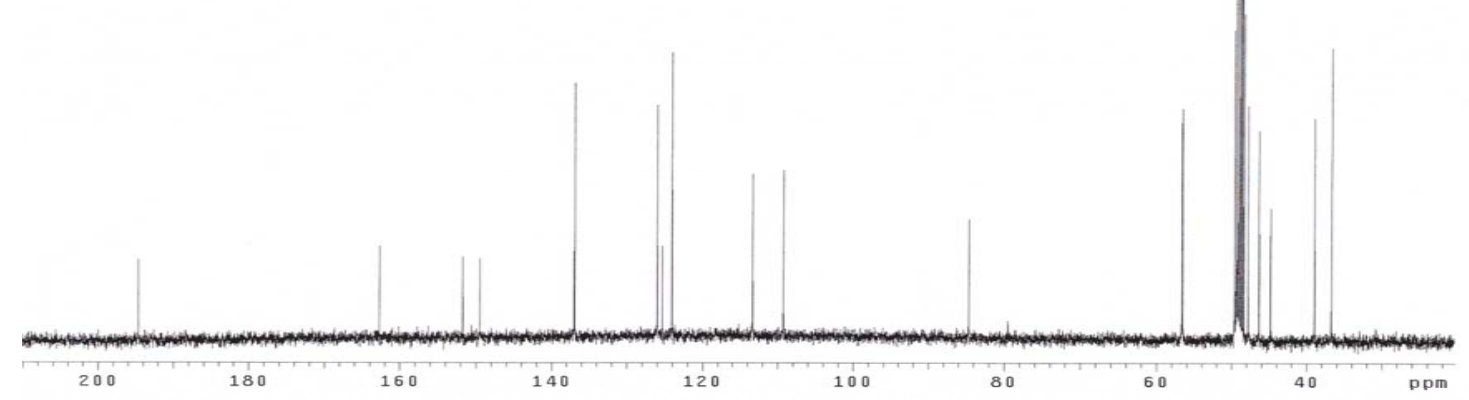

${ }^{13}$ C NMR Spectrum for Synthetic Cepharatine D

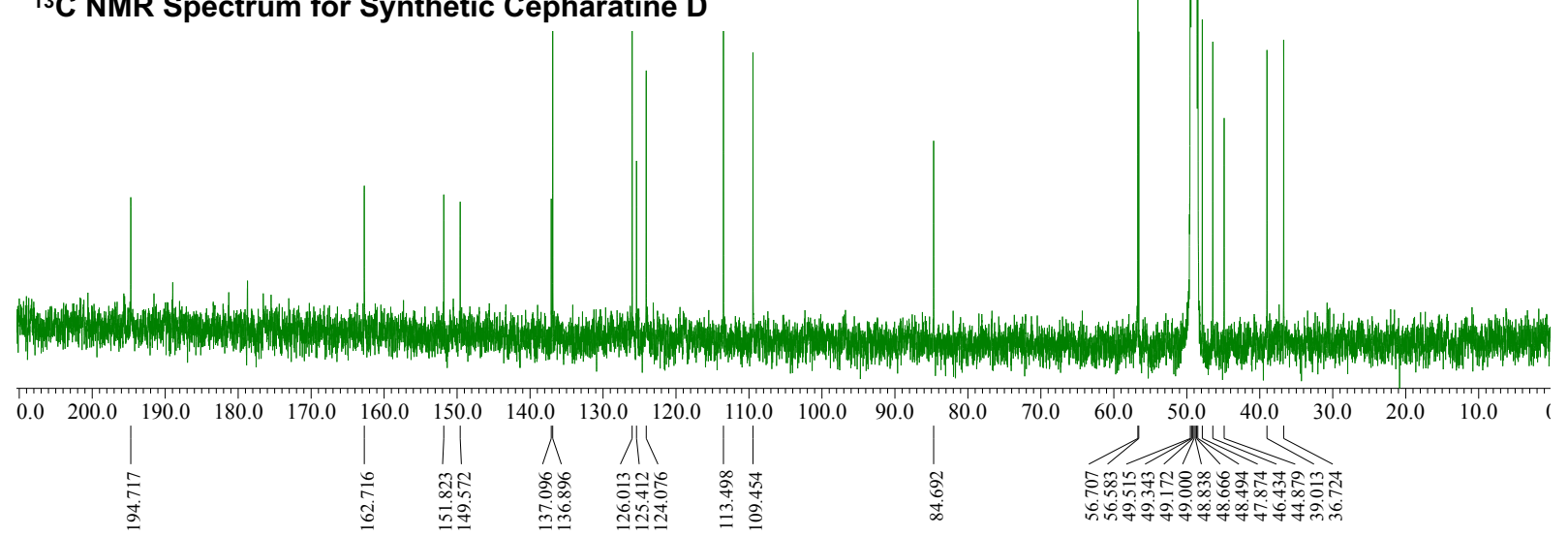




\section{4. ${ }^{1} \mathrm{H}$ and ${ }^{13} \mathrm{C}$ NMR Spectra}
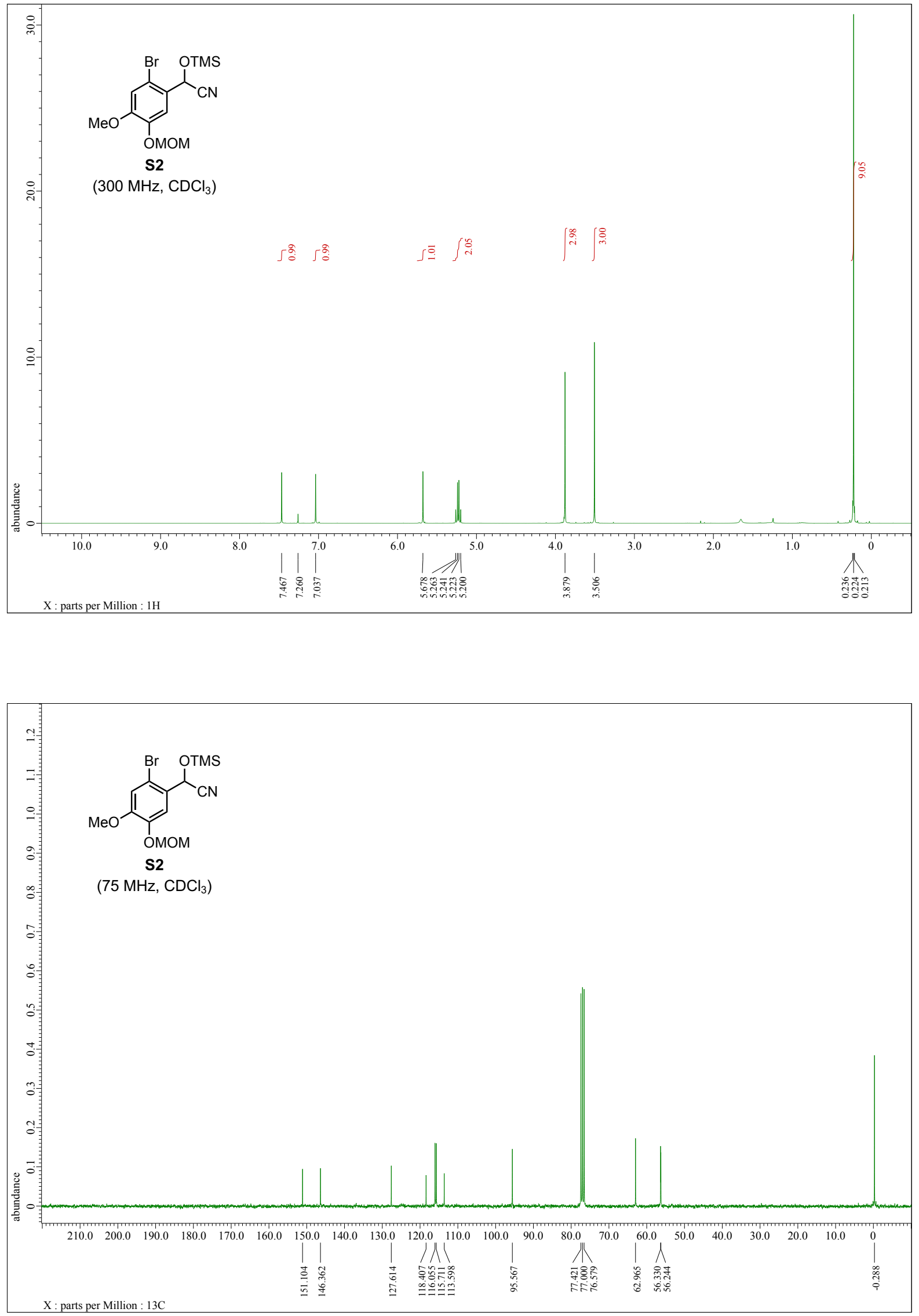

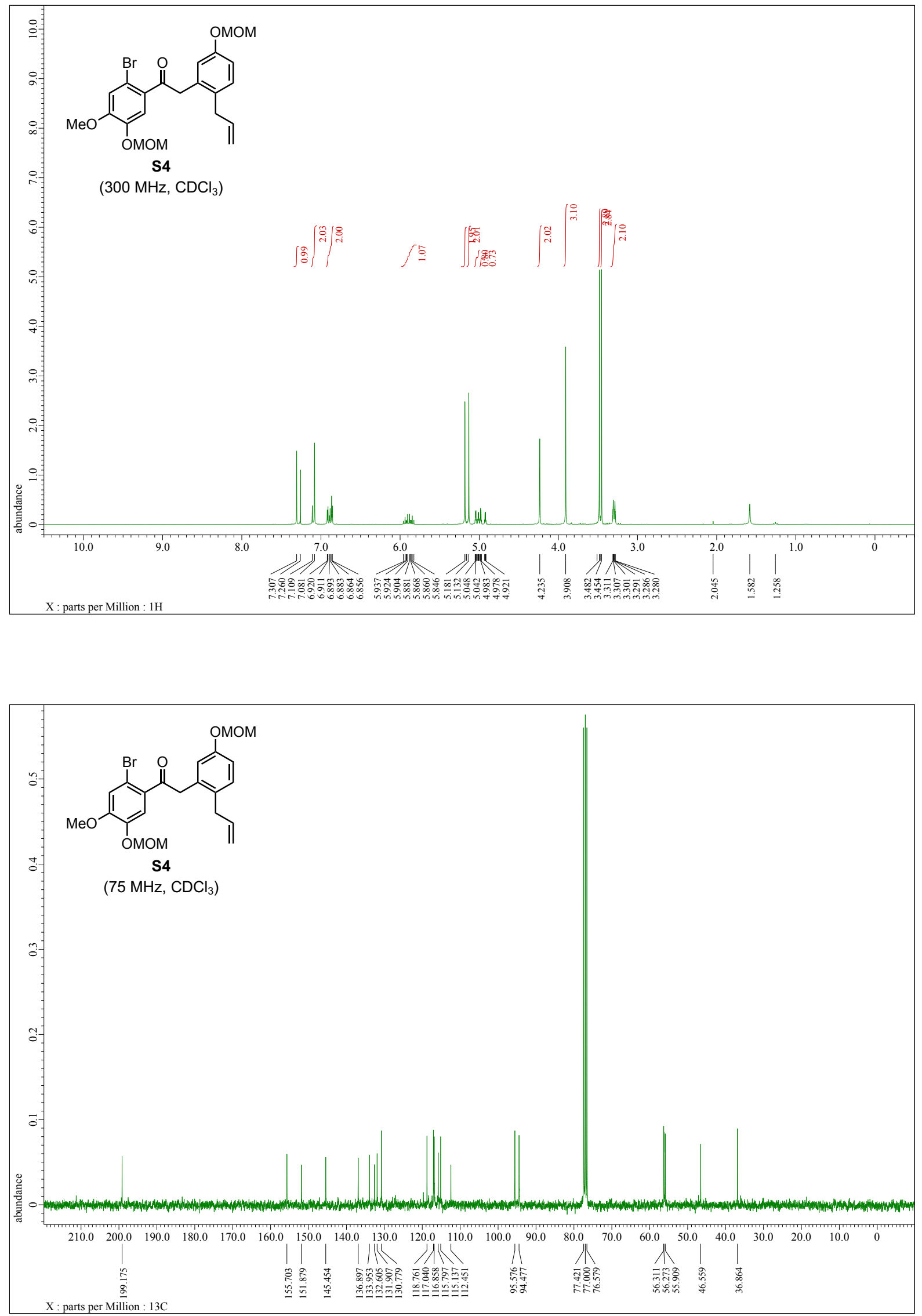

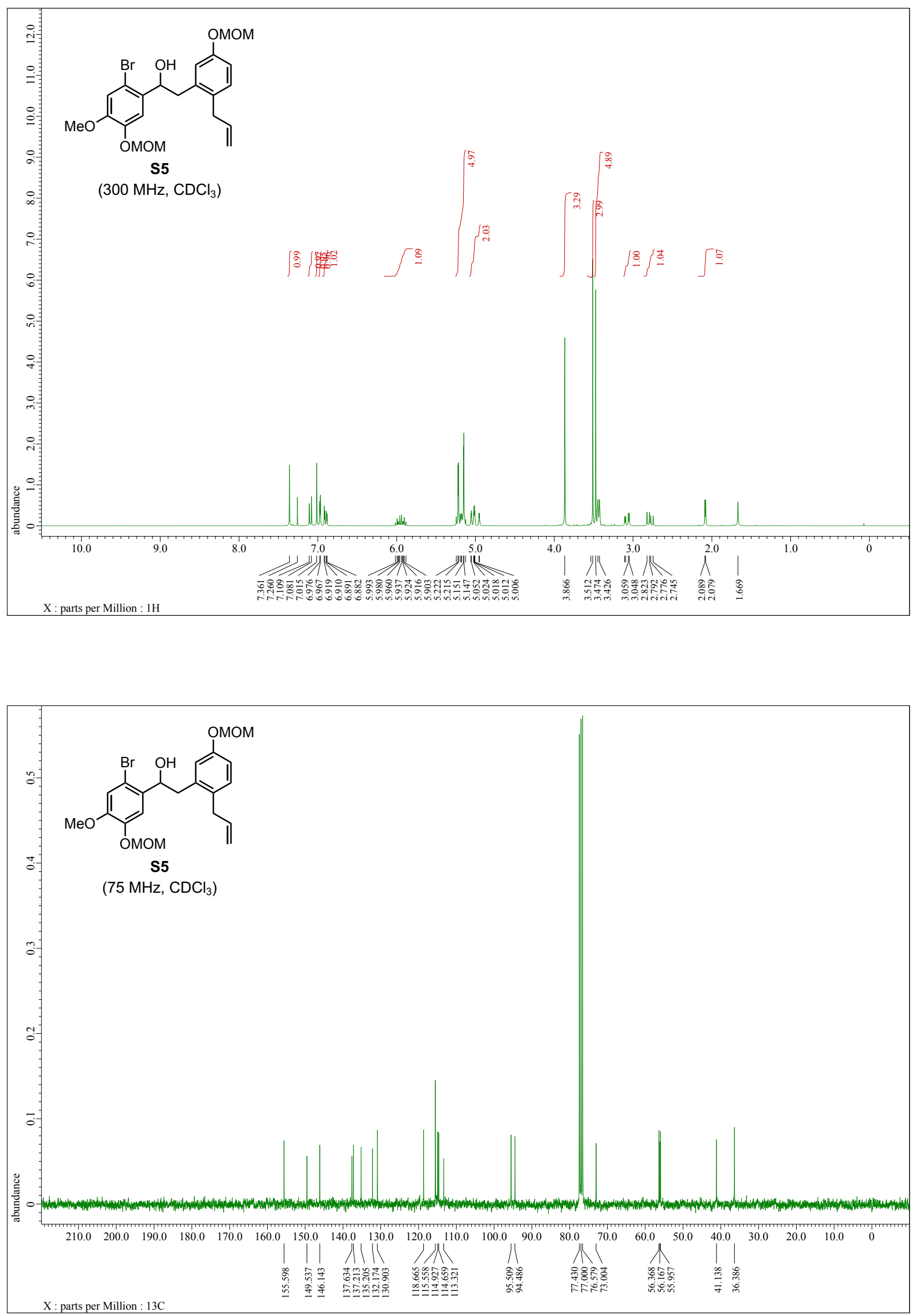

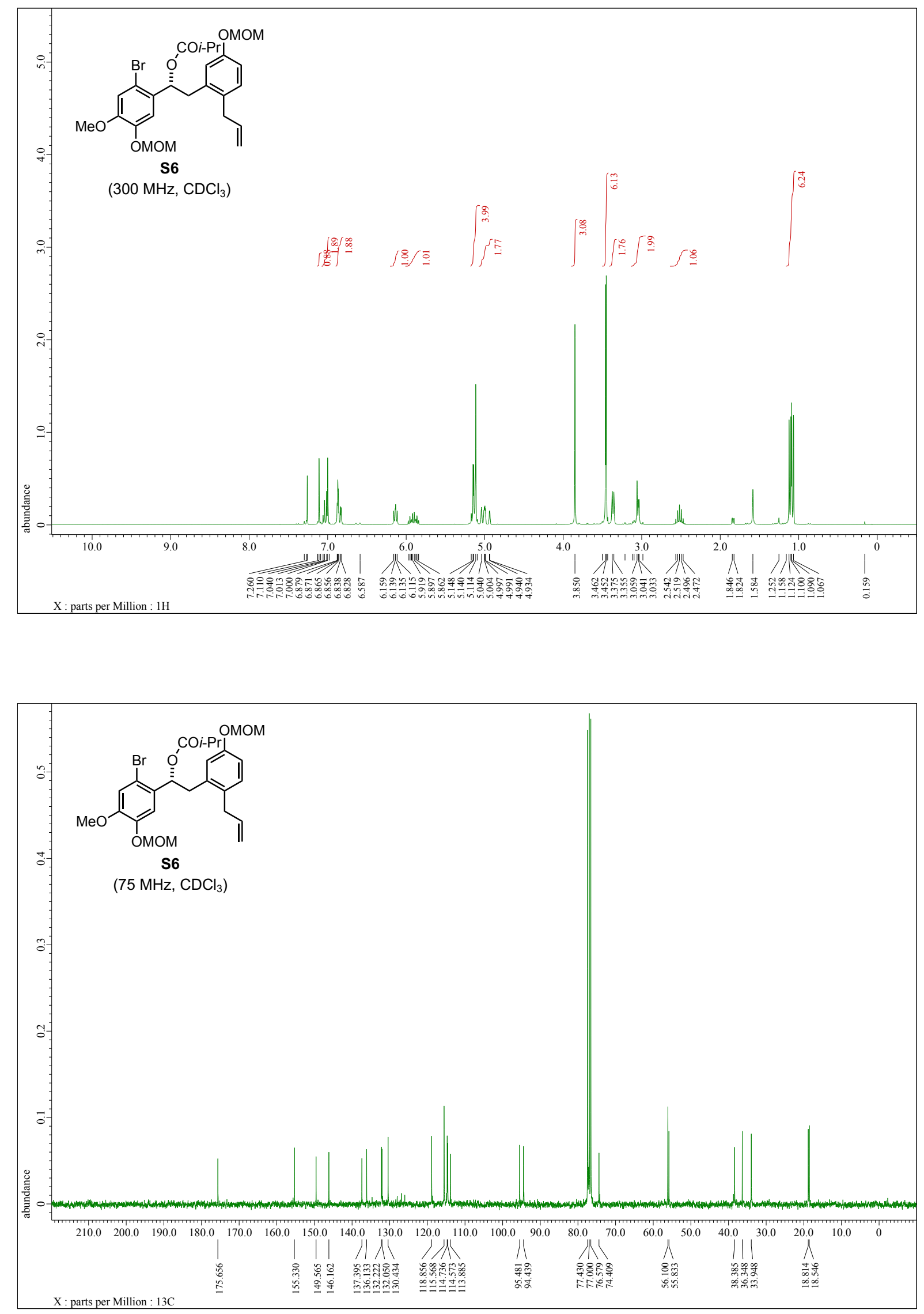

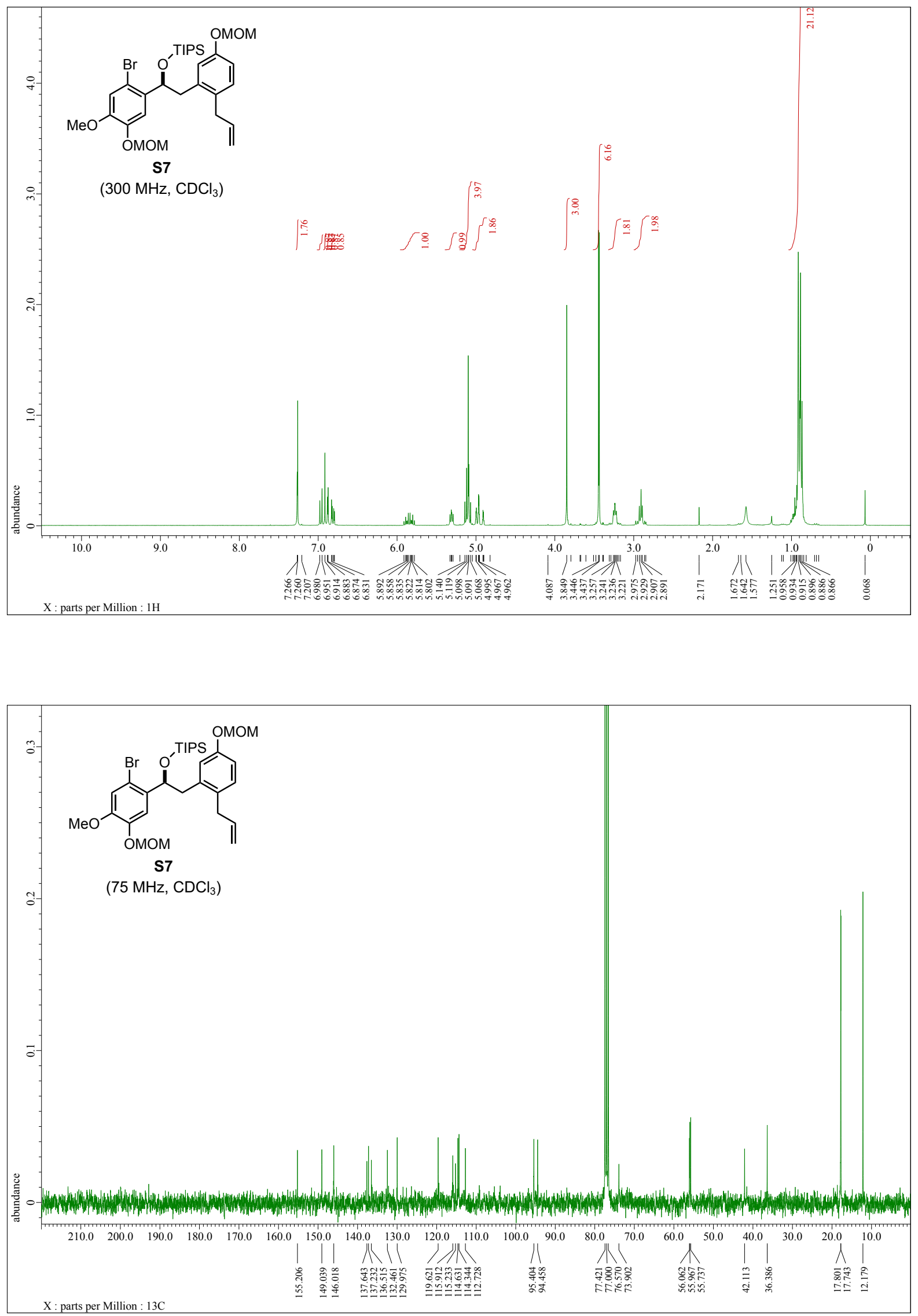

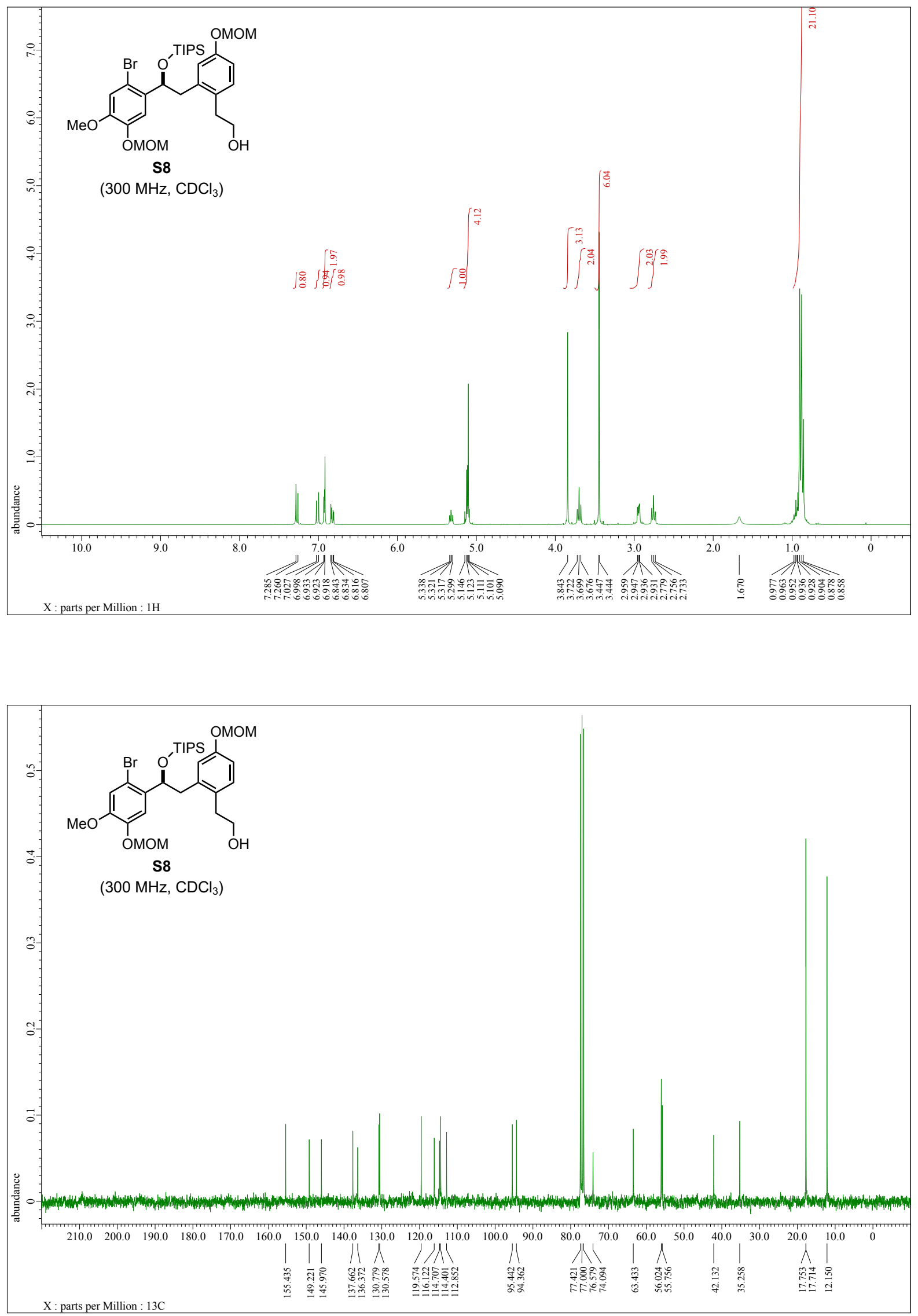

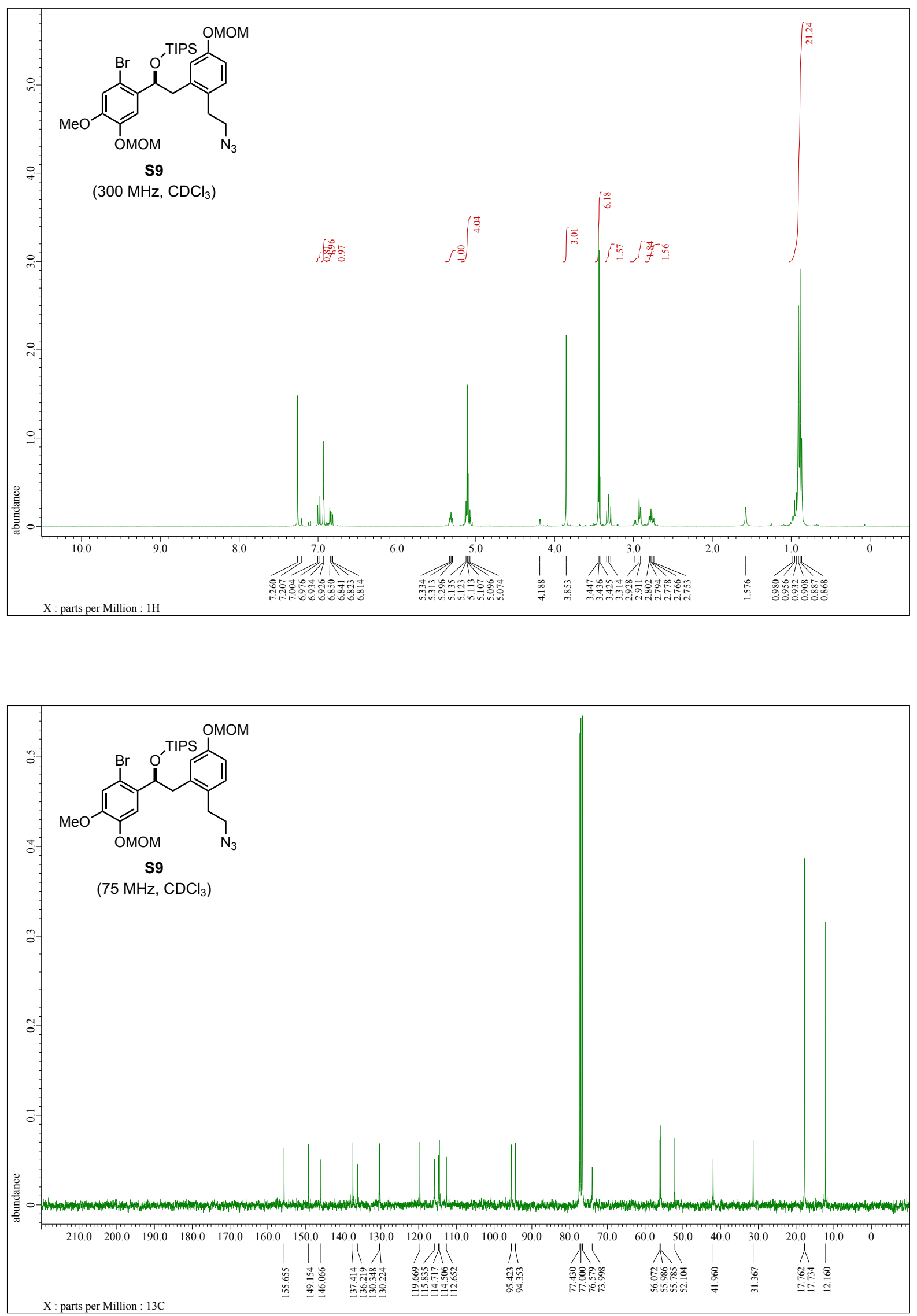

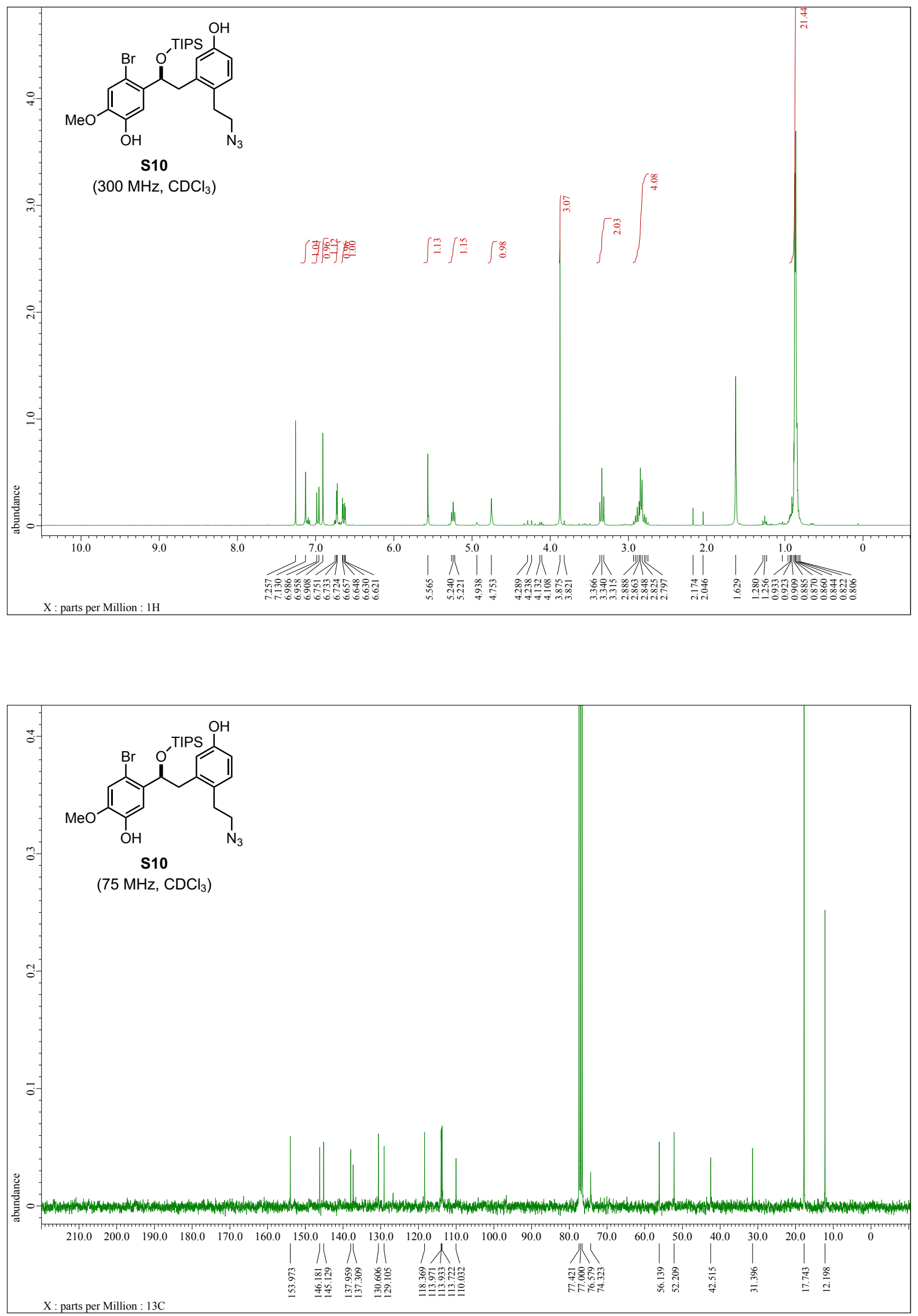

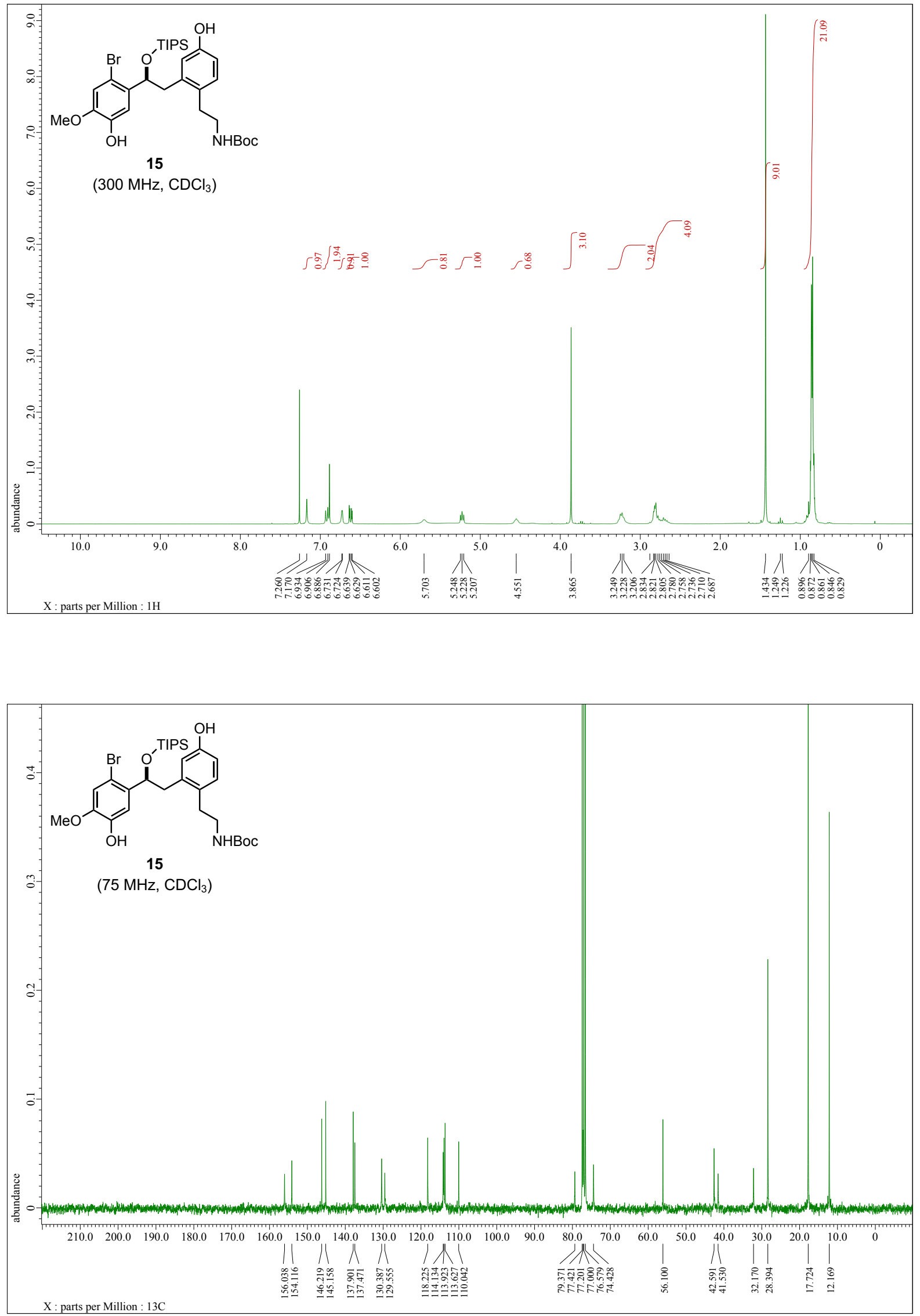

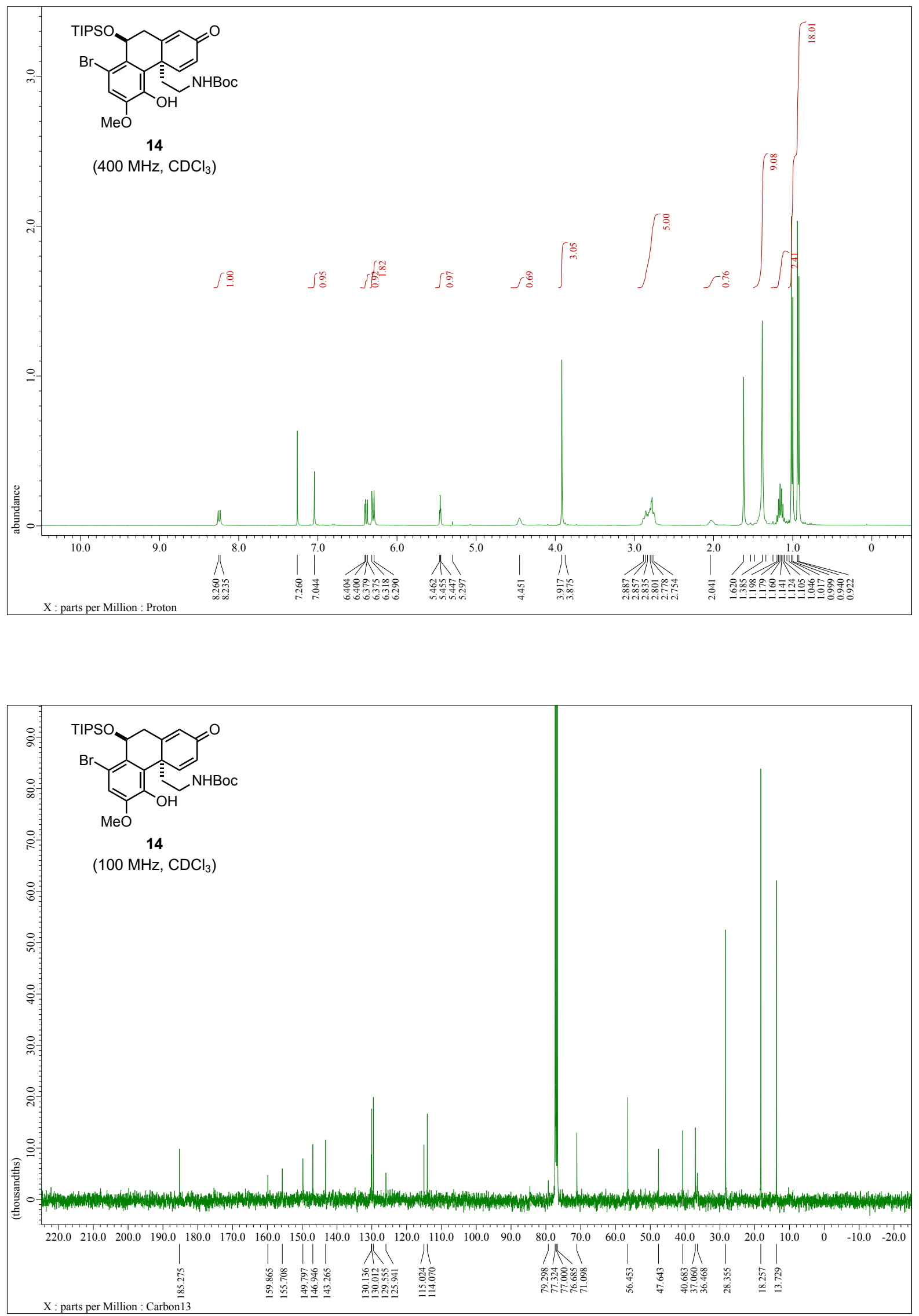

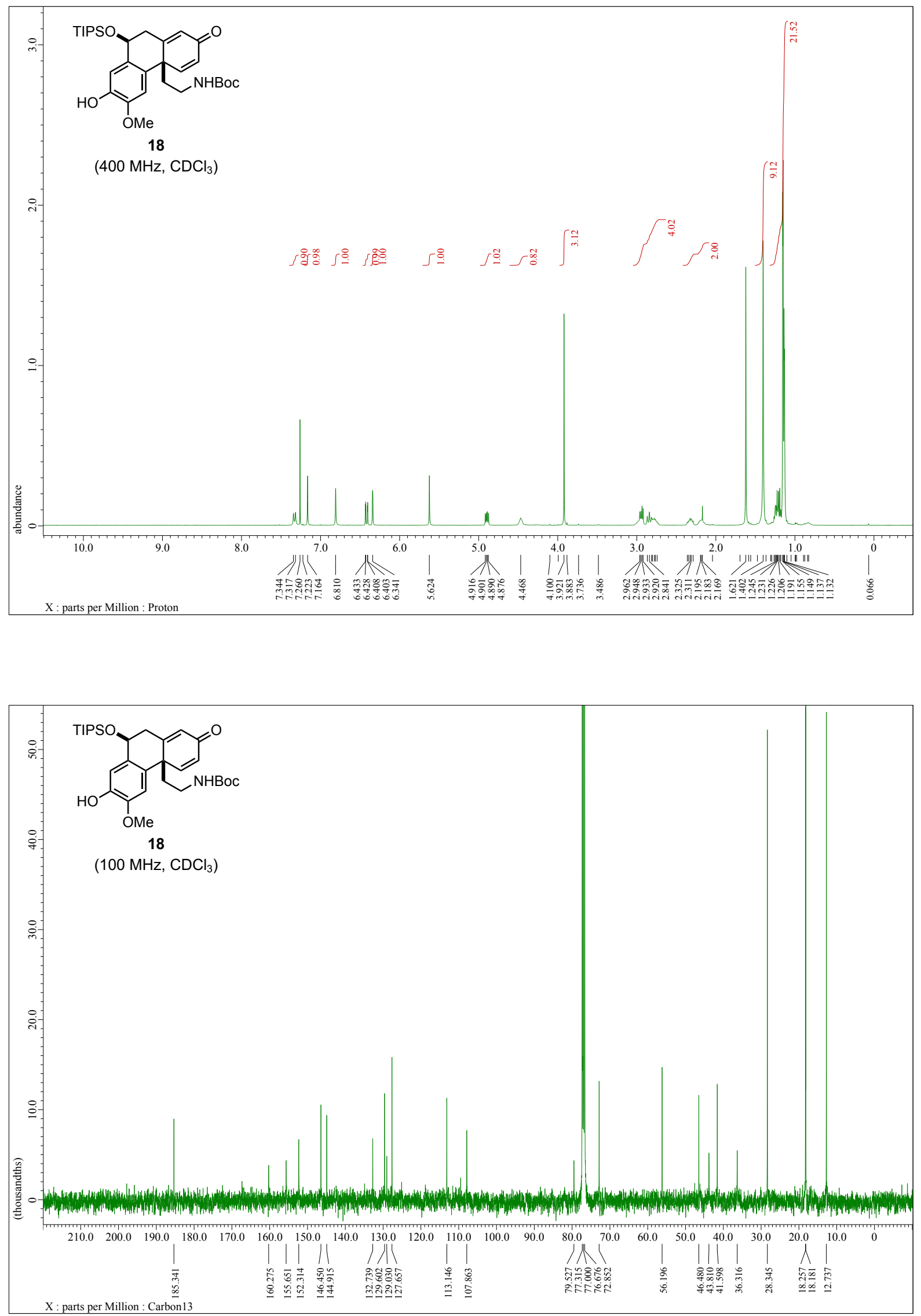
18 (2D-COSY, $400 \mathrm{MHz}, \mathrm{CDCl}_{3}$ )

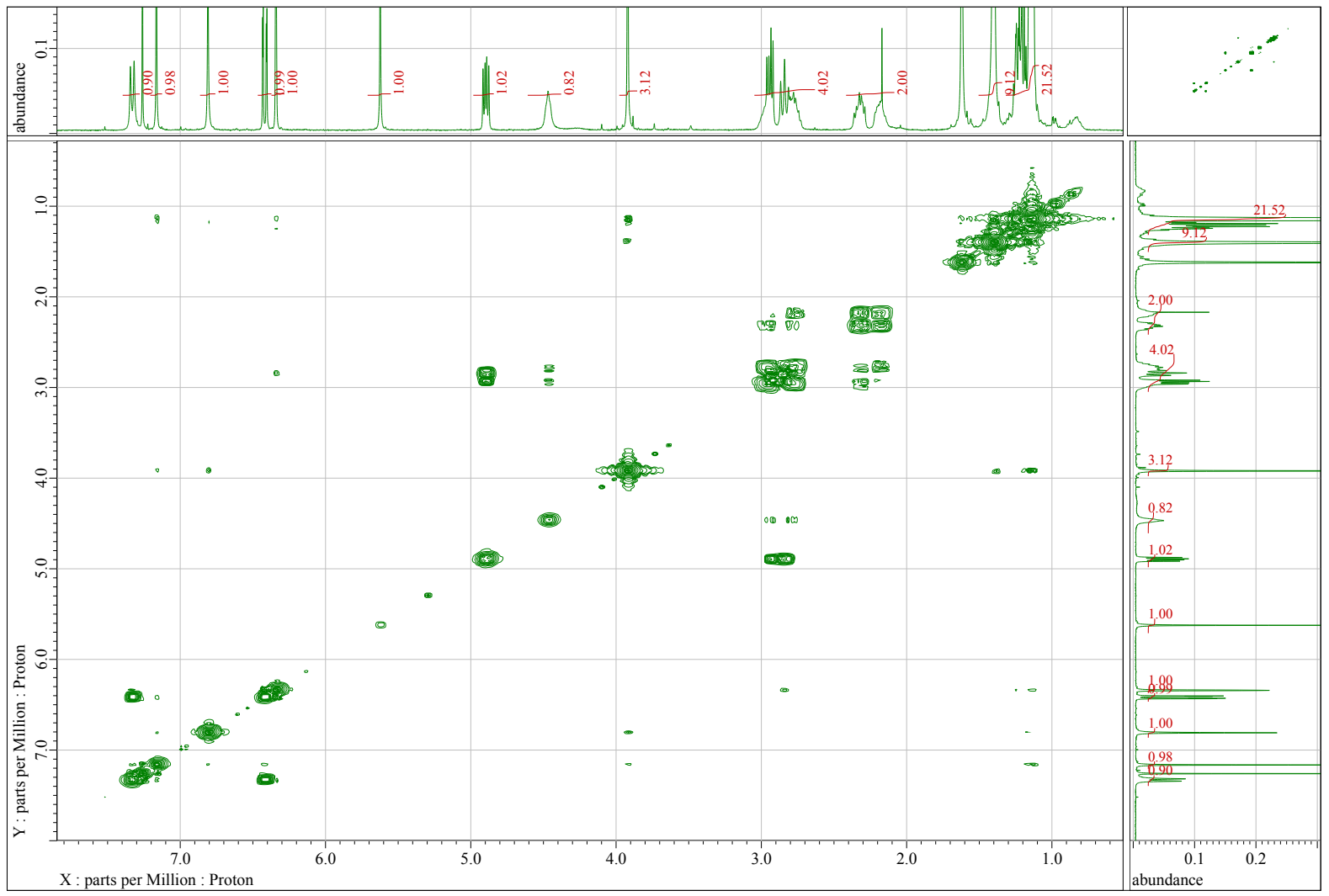

18 (2D-NOESY, $400 \mathrm{MHz}, \mathrm{CDCl}_{3}$ )

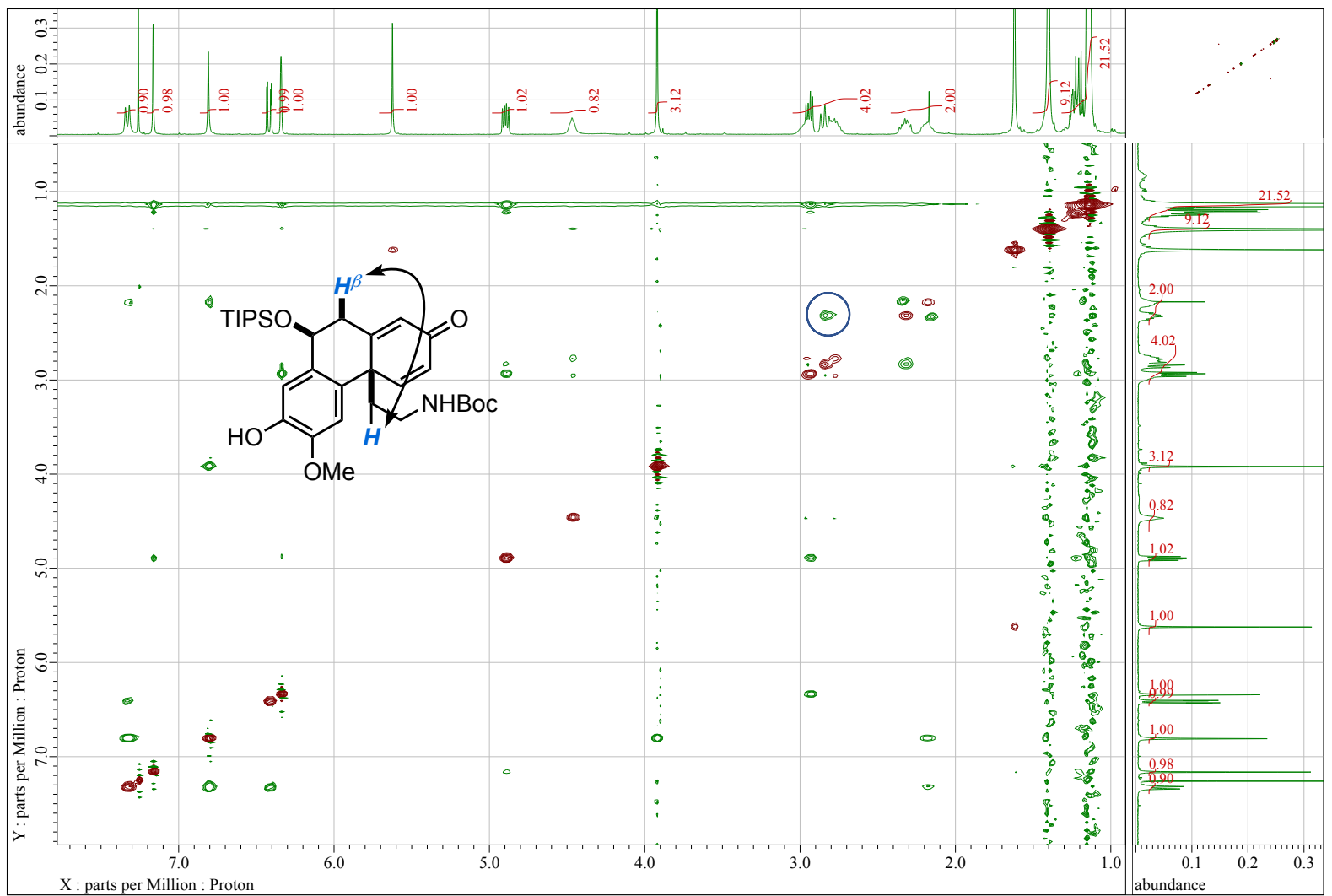



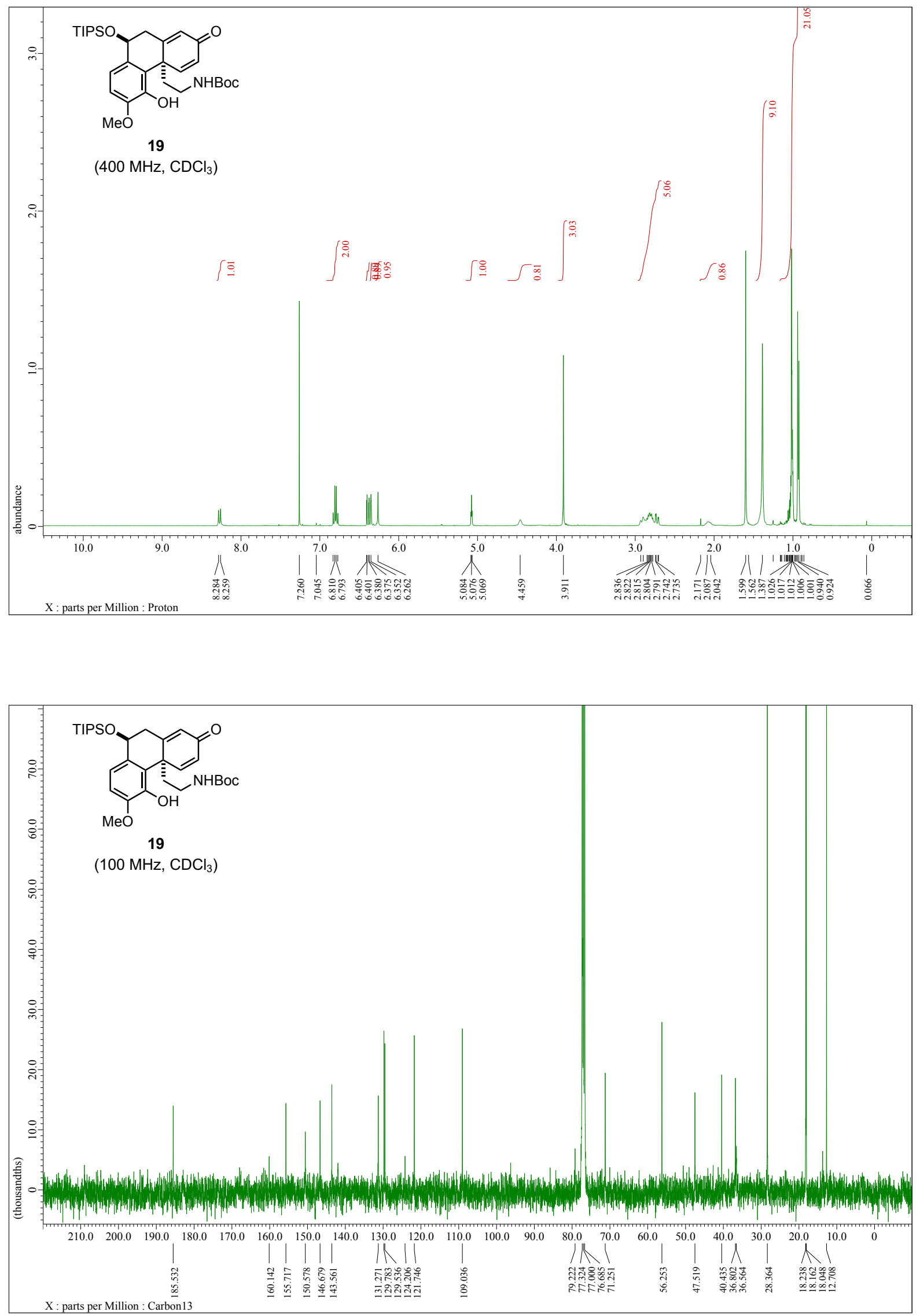

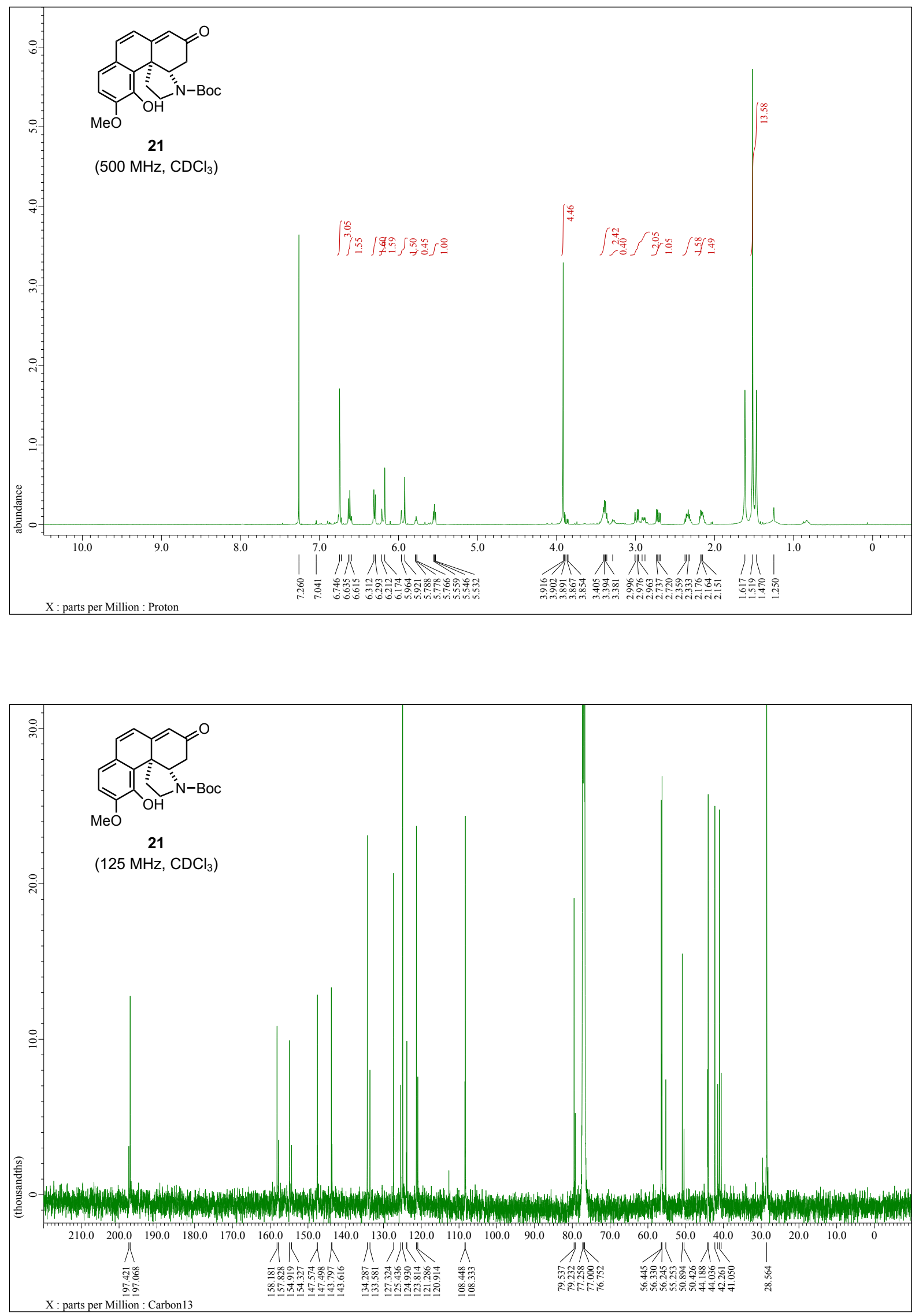

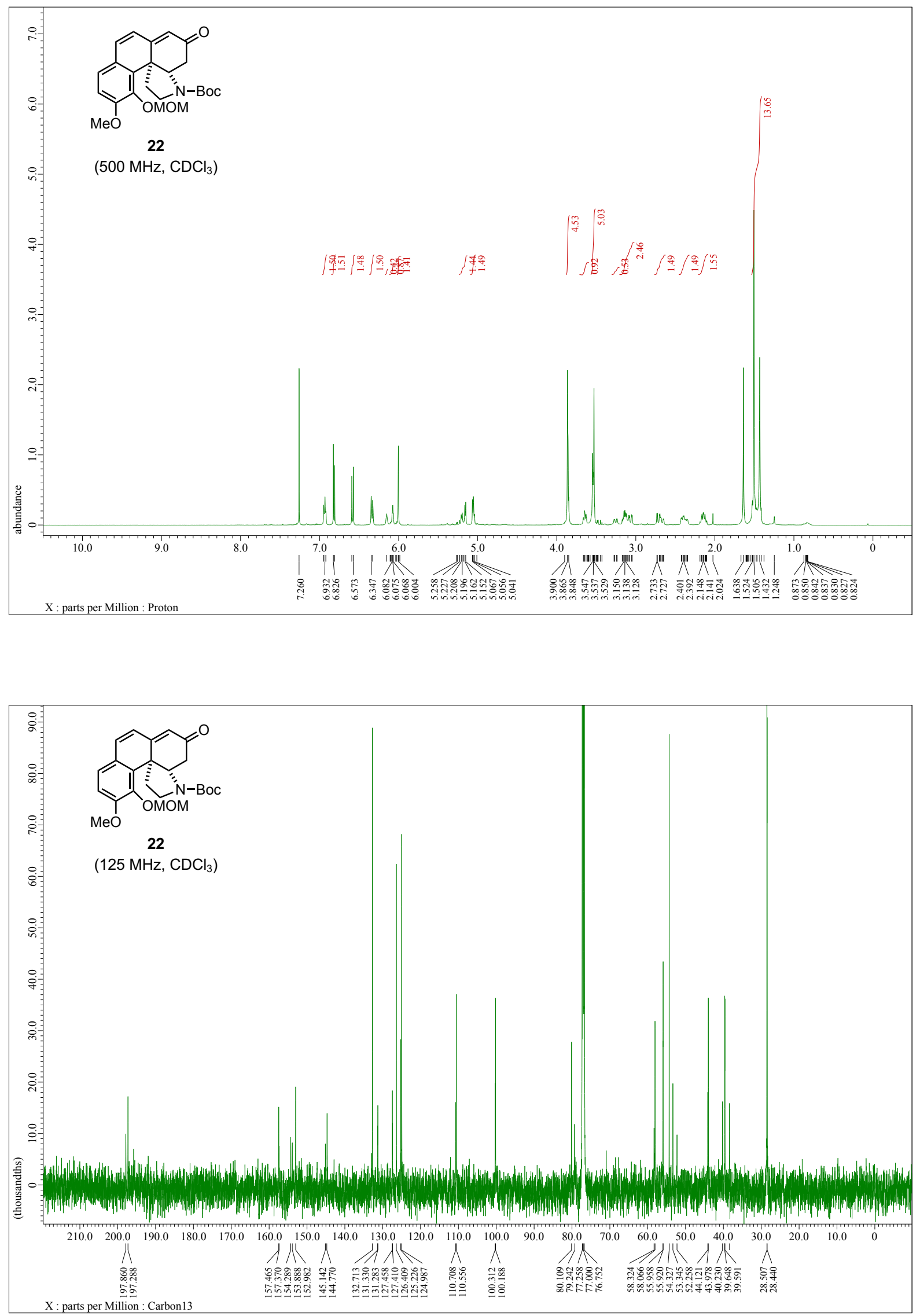

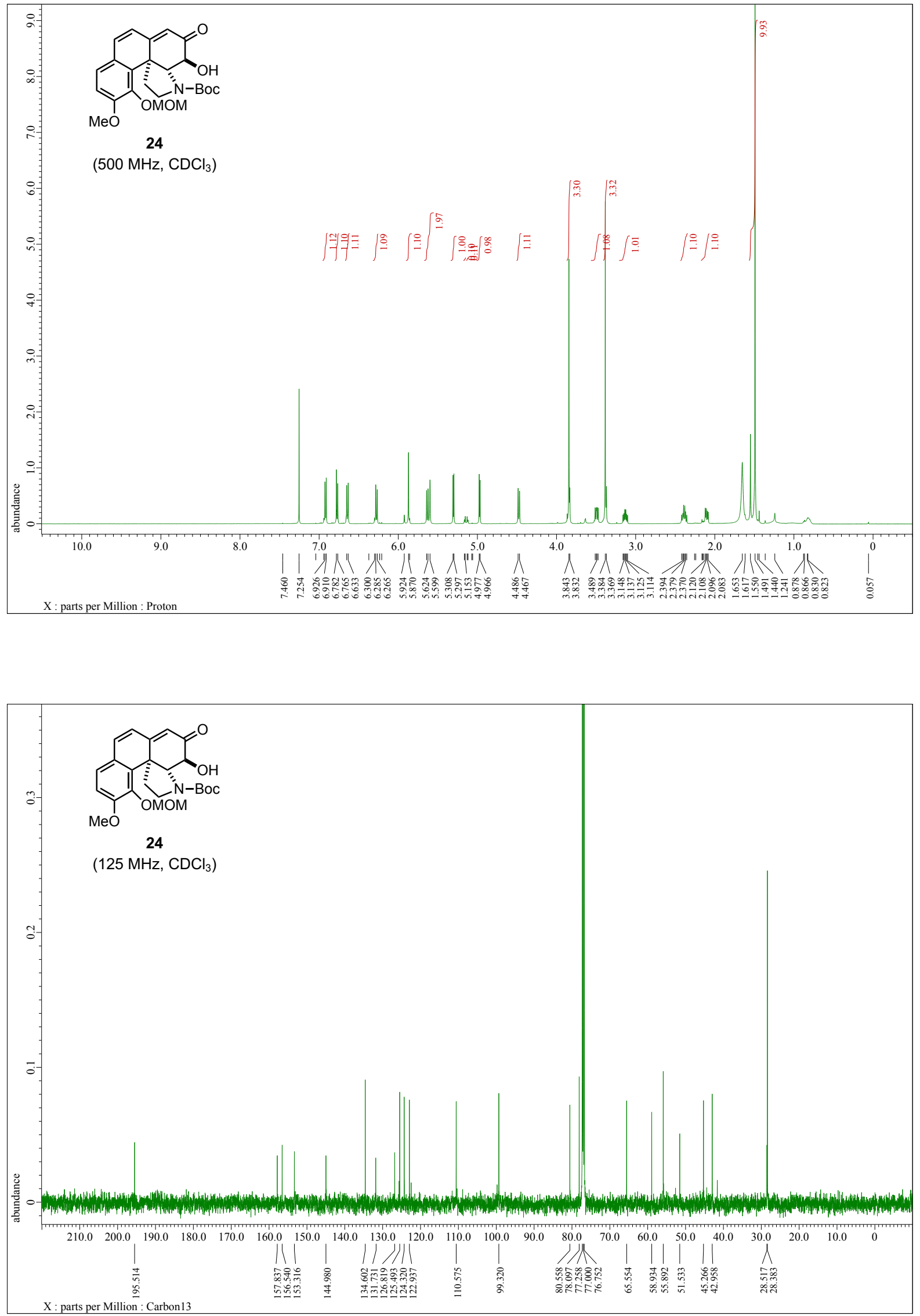
24 (2D-NOESY, $500 \mathrm{MHz}, \mathrm{CDCl}_{3}$ )

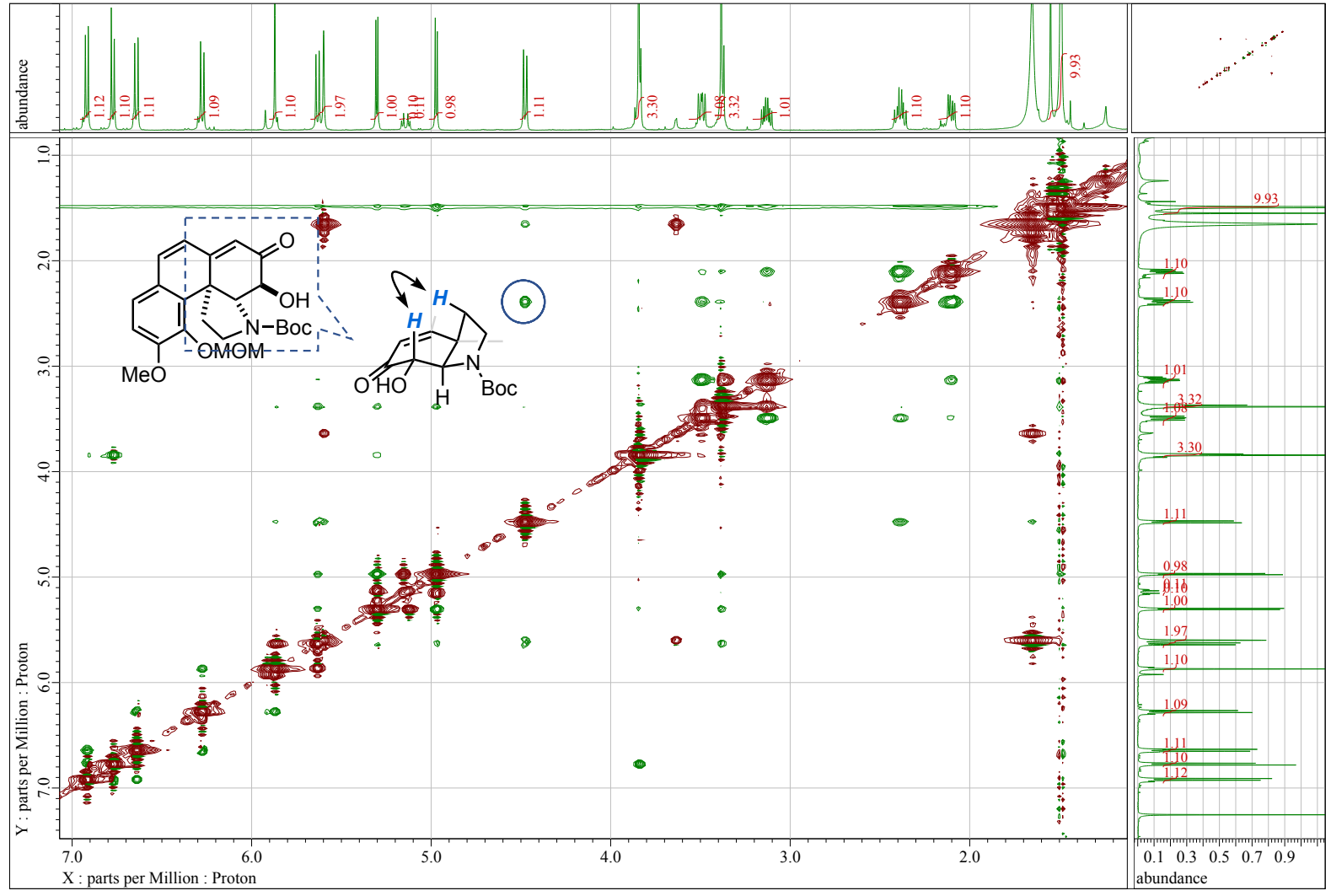



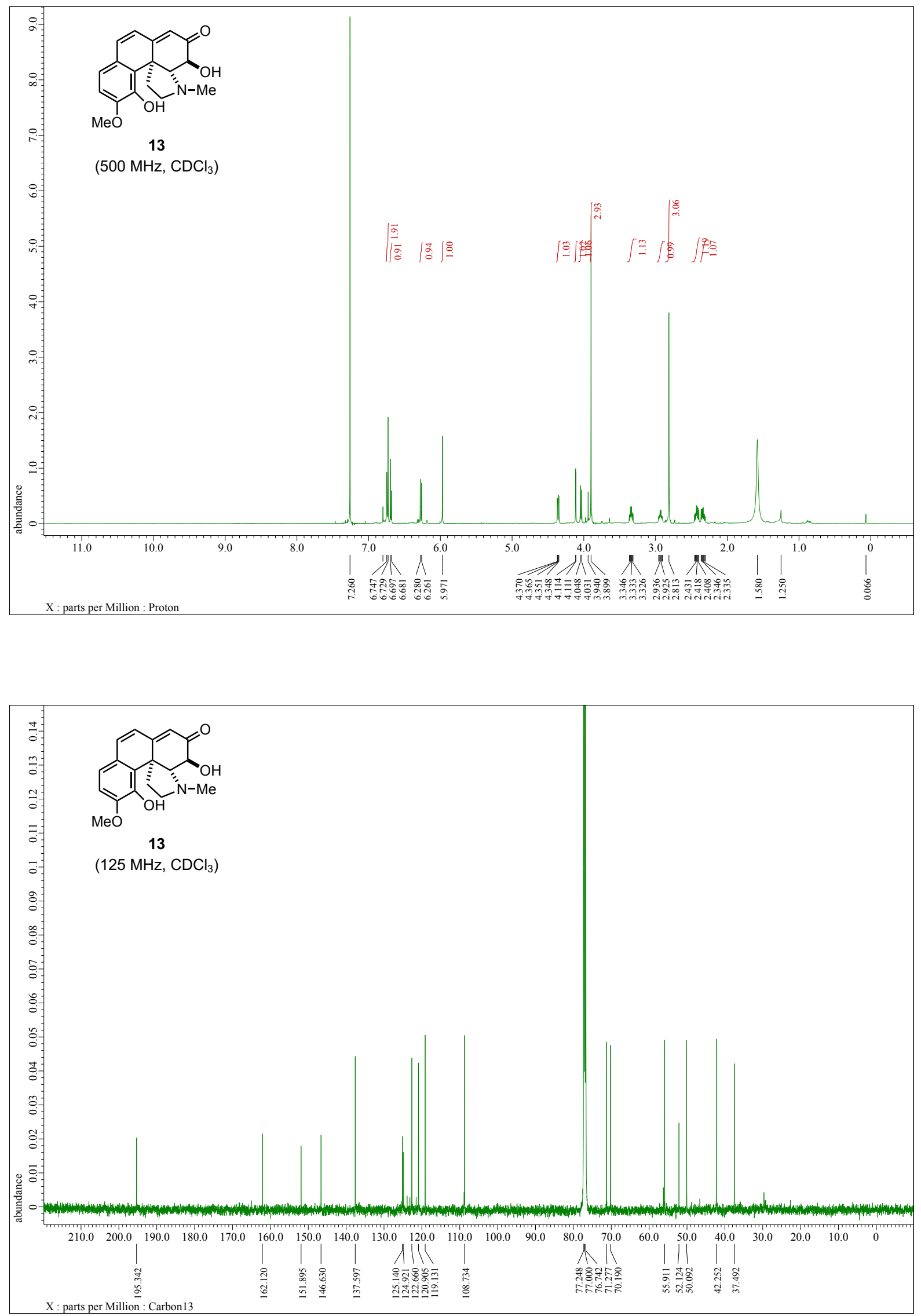
13 (2D-NOESY, $500 \mathrm{MHz}, \mathrm{CDCl}_{3}$ )

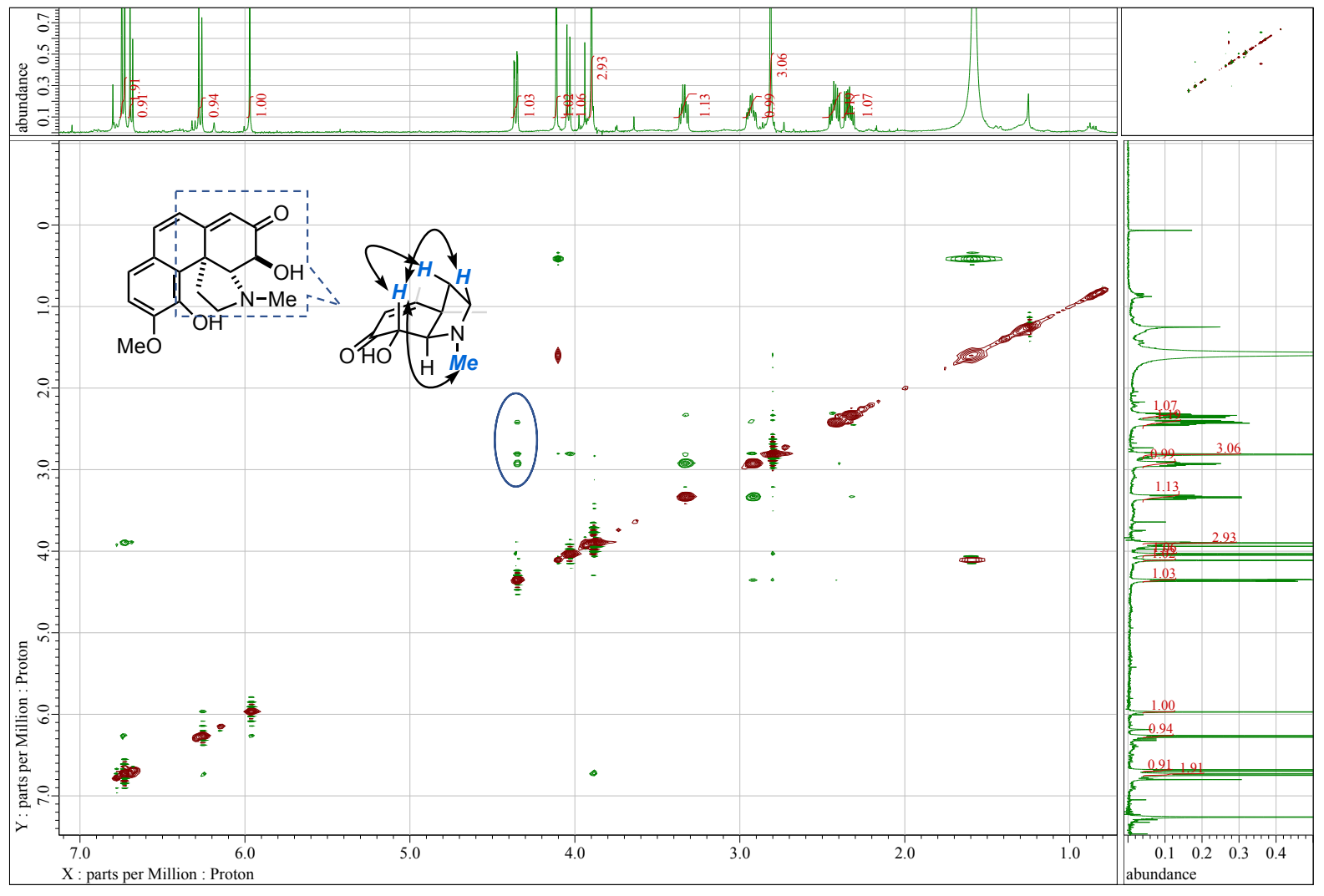



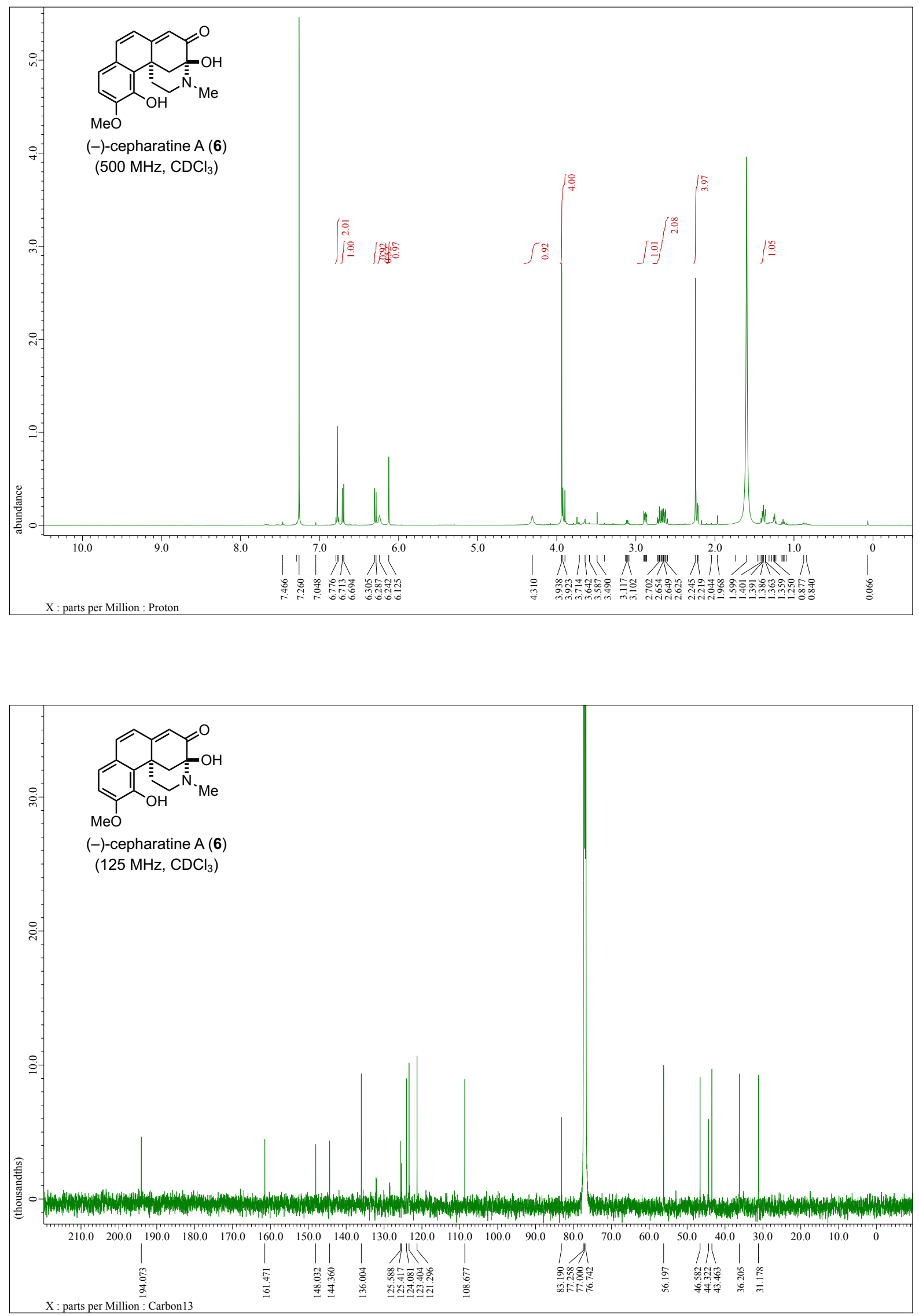

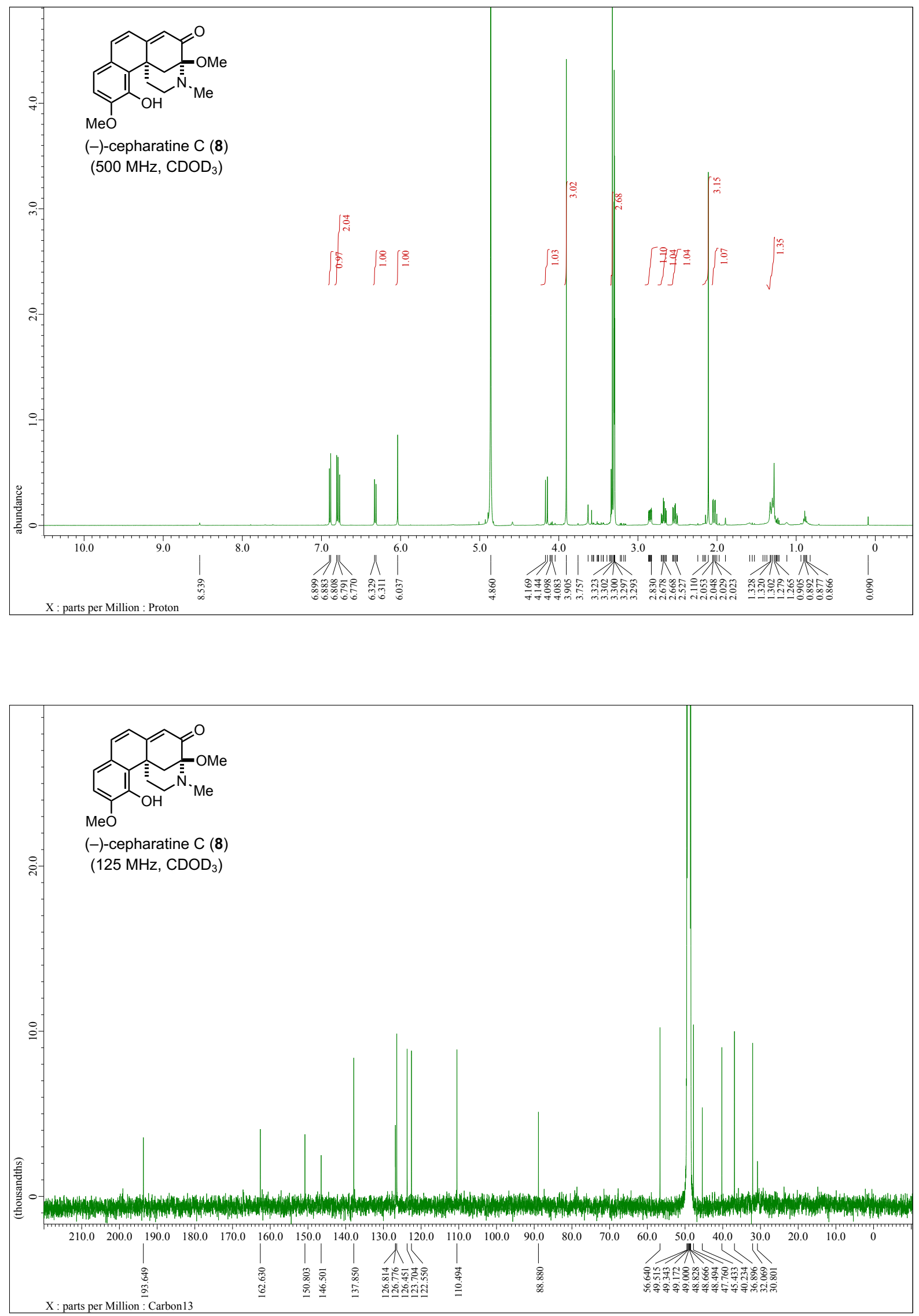

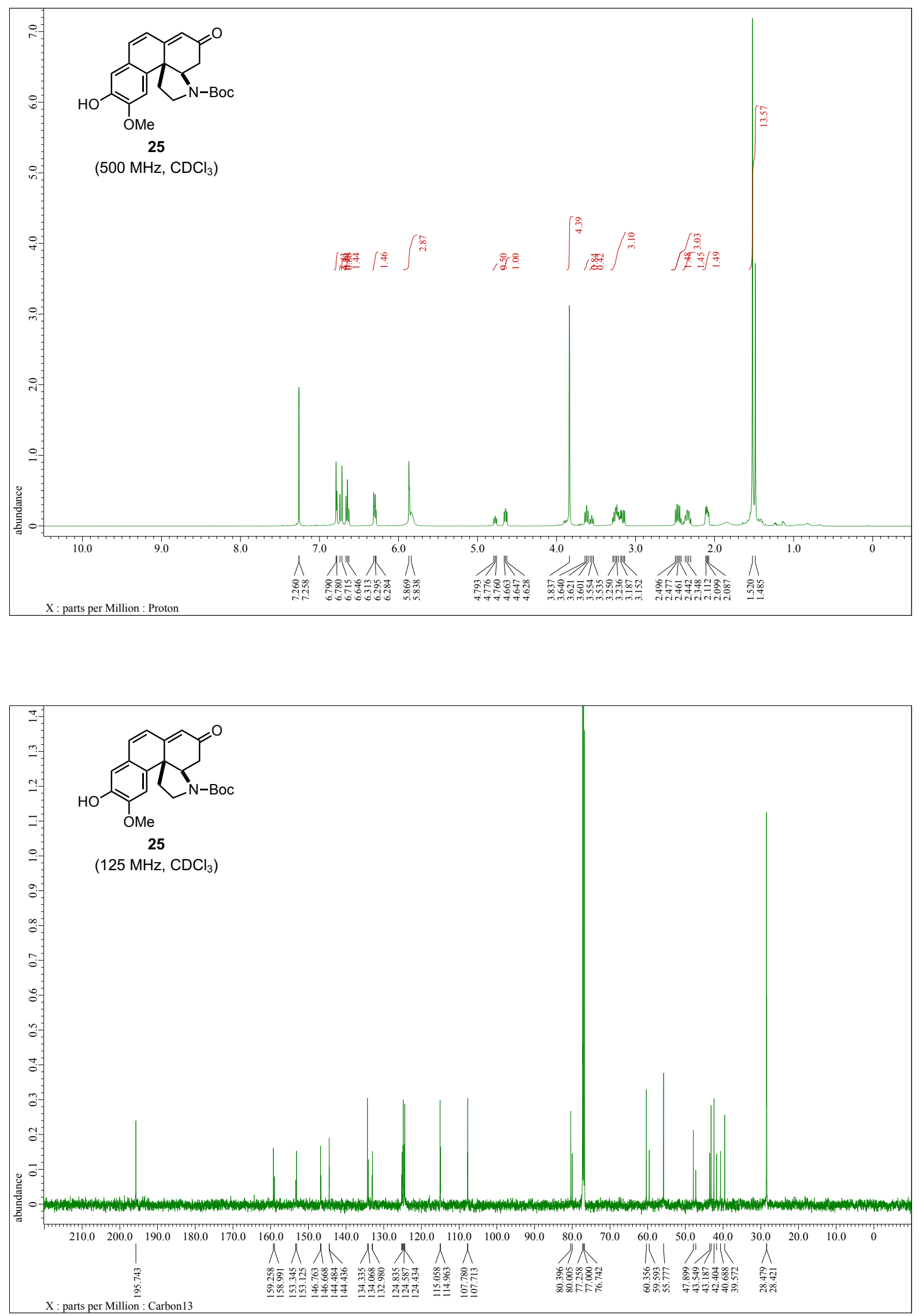

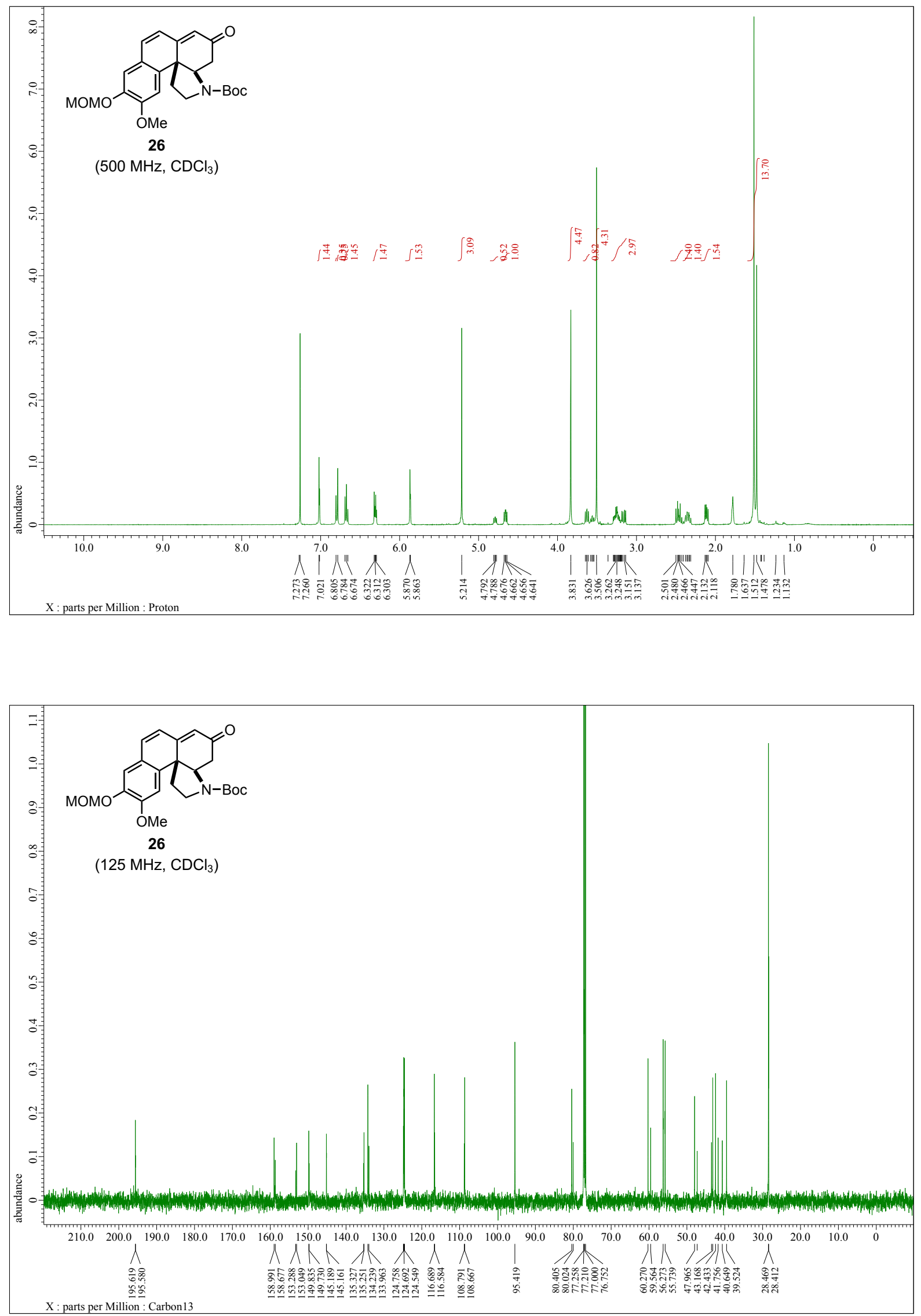

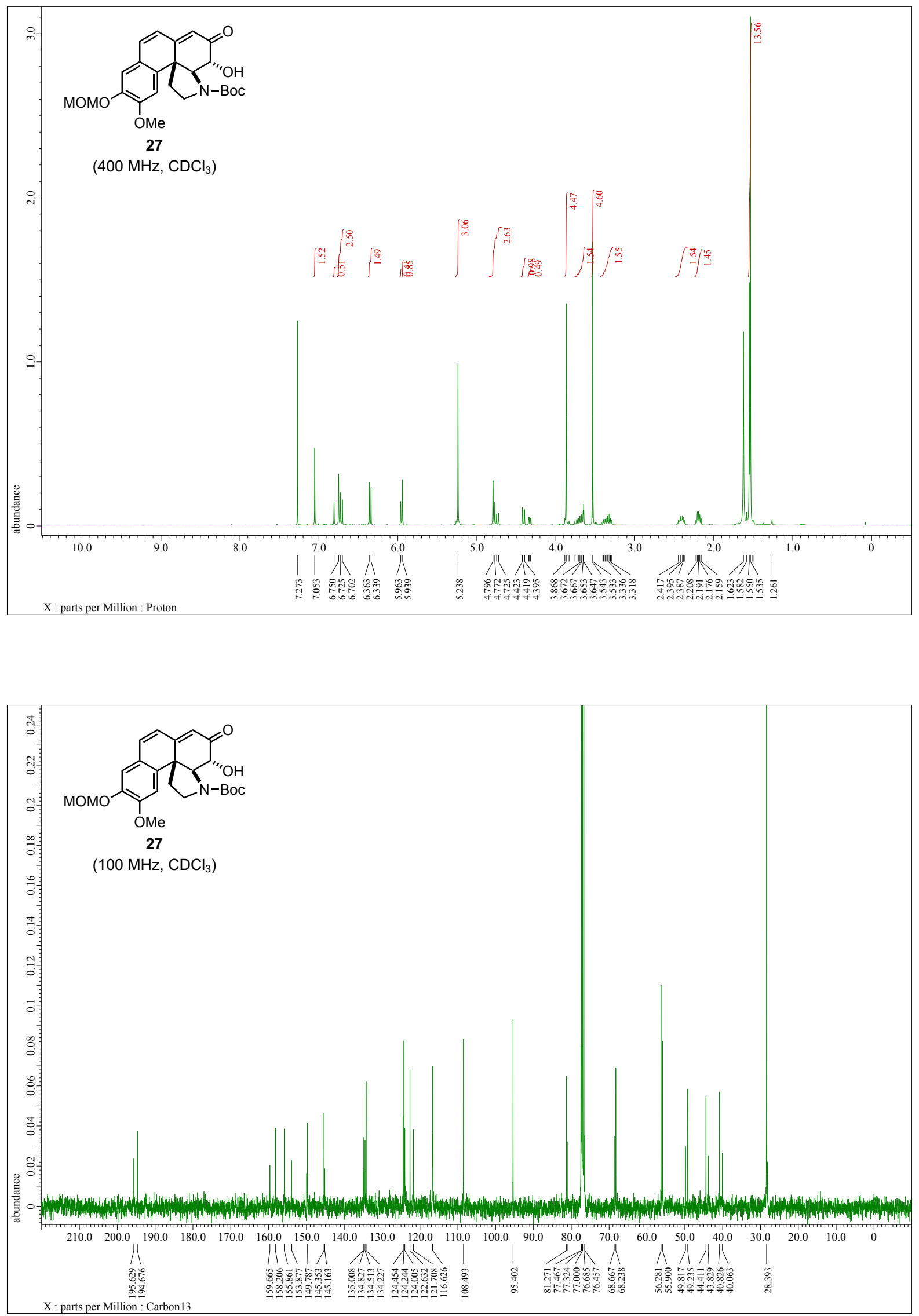
27 (2D-NOESY, $500 \mathrm{MHz}, \mathrm{CDCl}_{3}$ )

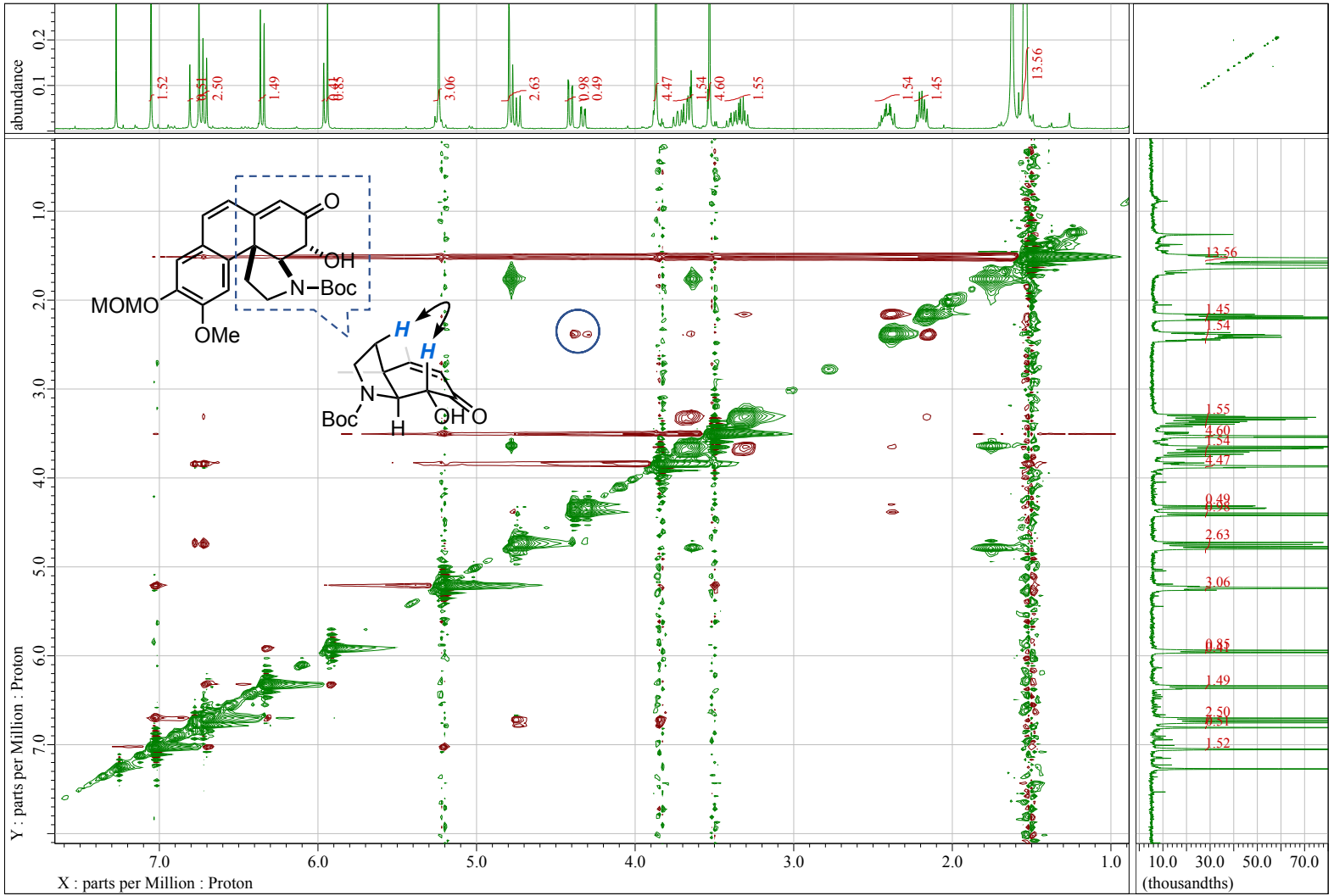



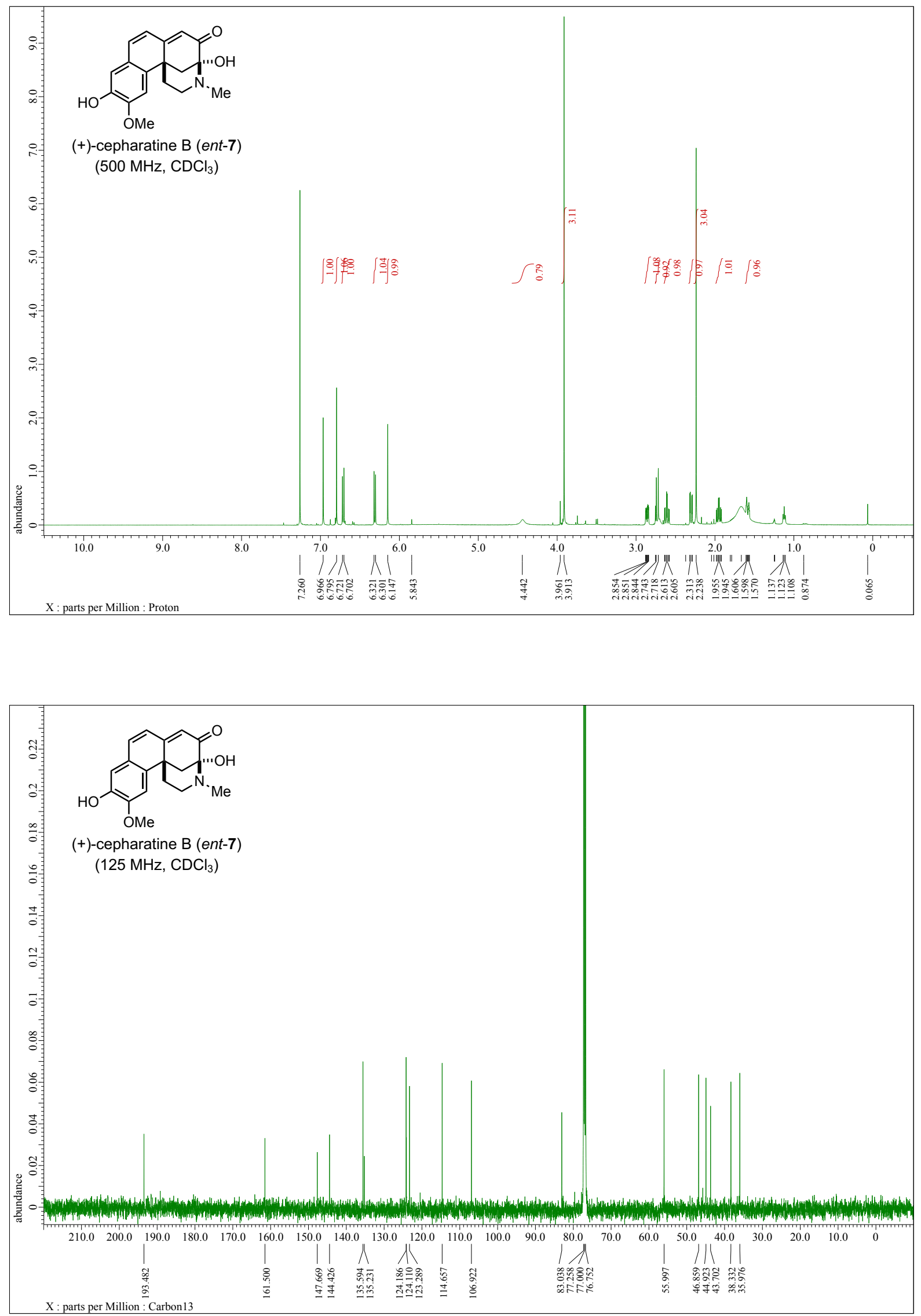

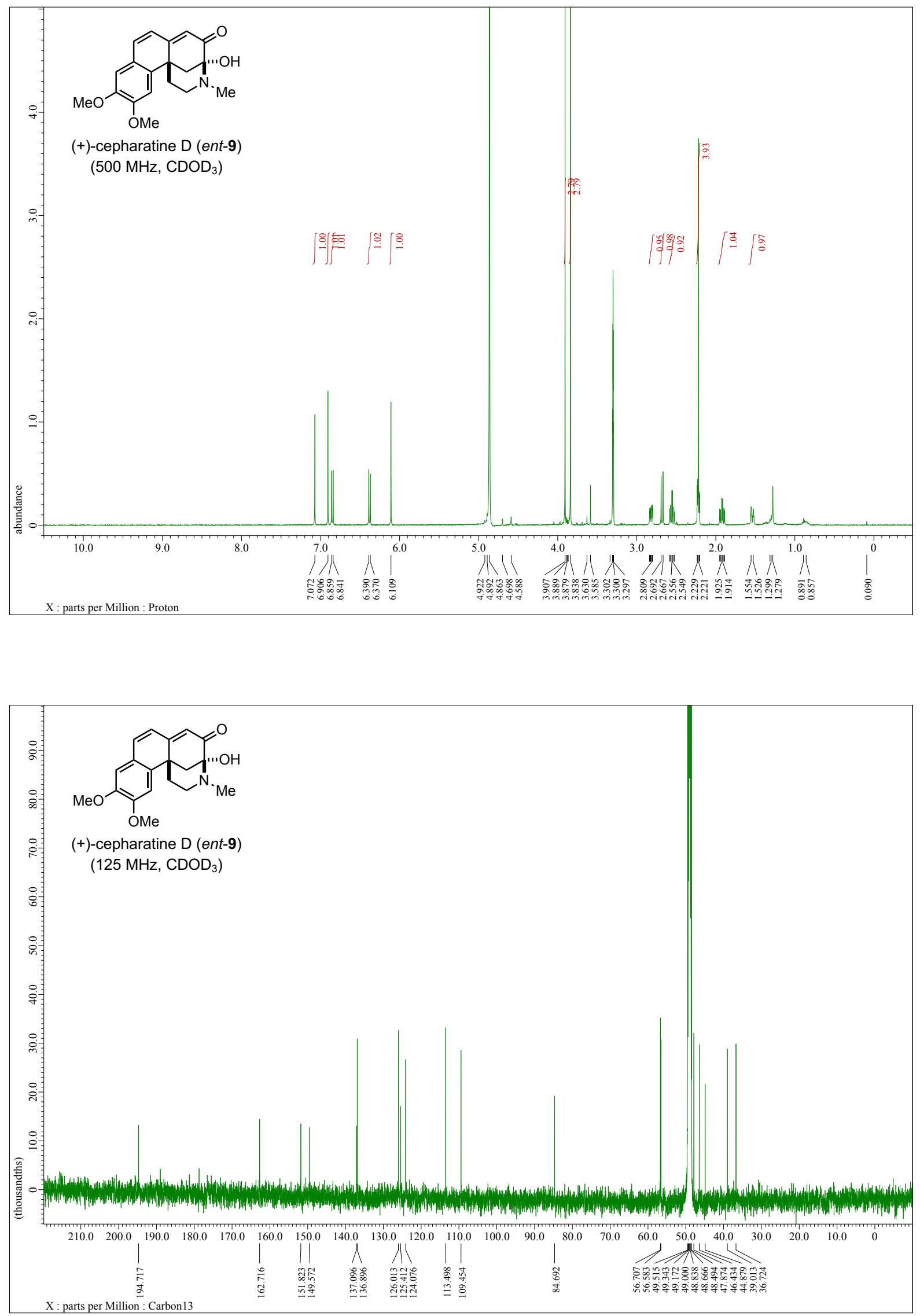